Illinois State University

ISU ReD: Research and eData

Theses and Dissertations

$11-7-2016$

\title{
Simulation Of Value Stream Mapping And Discrete Optimization Of Energy Consumption In Modular Construction
}

Md Mukul Chowdhury

Illinois State University, mukul.ch@hotmail.com

Follow this and additional works at: https://ir.library.illinoisstate.edu/etd

Part of the Civil Engineering Commons, and the Oil, Gas, and Energy Commons

\section{Recommended Citation}

Chowdhury, Md Mukul, "Simulation Of Value Stream Mapping And Discrete Optimization Of Energy Consumption In Modular Construction" (2016). Theses and Dissertations. 610.

https://ir.library.illinoisstate.edu/etd/610

This Thesis is brought to you for free and open access by ISU ReD: Research and eData. It has been accepted for inclusion in Theses and Dissertations by an authorized administrator of ISU ReD: Research and eData. For more information, please contact ISUReD@ilstu.edu. 


\title{
SIMULATION OF VALUE STREAM MAPPING AND DISCRETE OPTIMIZATION OF ENERGY CONSUMPTION IN MODULAR CONSTRUCTION
}

\author{
Md Mukul Chowdhury
}

89 Pages

With the increased practice of modularization and prefabrication, the construction industry gained the benefits of quality management, improved completion time, reduced site disruption and vehicular traffic, and improved overall safety and security. Whereas industrialized construction methods, such as modular and manufactured buildings, have evolved over decades, core techniques used in prefabrication plants vary only slightly from those employed in traditional site-built construction. With a focus on energy and cost efficient modular construction, this research presents the development of a simulation, measurement and optimization system for energy consumption in the manufacturing process of modular construction. The system is based on Lean Six Sigma principles and loosely coupled system operation to identify the non-value adding tasks and possible causes of low energy efficiency. The proposed system will also include visualization functions for demonstration of energy consumption in modular construction. The benefits of implementing this system include a reduction in the energy consumption in production cost, decrease of energy cost in the production of lean-modular construction, and increase profit. In addition, the visualization functions will provide detailed information about energy efficiency and operation flexibility in modular construction. A case study is presented to validate the reliability of the system. KEYWORDS: Modular Construction, Lean Six Sigma, Energy Consumption, Value Stream Mapping, Discrete Optimization. 


\title{
SIMULATION OF VALUE STREAM MAPPING AND DISCRETE OPTIMIZATION OF ENERGY CONSUMPTION IN MODULAR CONSTRUCTION
}

\author{
MD MUKUL CHOWDHURY
}

A Thesis Submitted in Partial Fulfilment of the Requirements for the Degree of

\section{MASTER OF SCIENCE}

Department of Technology

ILLINOIS STATE UNIVERSITY 
(C) 2016 Md Mukul Chowdhury 
SIMULATION OF VALUE STREAM MAPPING AND DISCRETE OPTIMIZATION OF ENERGY CONSUMPTION IN MODULAR CONSTRUCTION

MD MUKUL CHOWDHURY

COMMITTEE MEMBERS:

Haiyan Xie, Chair

Klaus Schmidt

Richard Boser 


\section{ACKNOWLEDGMENTS}

I would like to thank God for giving me the strength and good health every day to carry on my work. I would also like to thank the members of the thesis committee, my friends and family for their endless help and support towards the completion of my thesis. I am also grateful to Homeway Homes Construction Facility and Darnall Concrete Inc. for helping me to understand the process in order to build the model.

M.C. 


\section{CONTENTS}

Page

ACKNOWLEDGEMENTS $\quad$ i

$\begin{array}{ll}\text { CONTENTS } & \text { ii }\end{array}$

TABLES $\quad$ V

FIGURES

CHAPTER I: INTRODUCTION 1

Lean Six Sigma Principles in Modular Construction 5

$\begin{array}{ll}\text { Aim of the Thesis and Research Question } & 7\end{array}$

$\begin{array}{ll}\text { Significance of the study } & 7\end{array}$

$\begin{array}{lr}\text { Assumptions } & 9\end{array}$

Hypotheses and Limitations $\quad 9$

CHAPTER II: LITERATURE REVIEW 11

$\begin{array}{ll}\text { Modular Construction } & 11\end{array}$

$\begin{array}{ll}\text { Lean Six Sigma } & 12\end{array}$

Lean Principles 15

$\begin{array}{ll}\text { Application of Lean in Construction Industry } & 17\end{array}$

Key Principles of Six Sigma 19

Combined Application of Lean and Six Sigma in Modular Construction 23

$\begin{array}{ll}\text { Value Stream Mapping (VSM) } & 25\end{array}$

Sustainability and Energy Consumption 33

Energy Consumption Using System Dynamics Approach 34

Discrete Optimization in Modular Construction Production 34 
Overview of Methodology 36

$\begin{array}{ll}\text { Proposed Framework } & 37\end{array}$

$\begin{array}{ll}\text { Value Stream Mapping (VSM): } & 37\end{array}$

$\begin{array}{ll}\text { System Dynamics (SD) for Verification } & 38\end{array}$

$\begin{array}{ll}\text { loosely Coupled Multi-Unit System } & 41\end{array}$

$\begin{array}{ll}\text { Discrete Optimization } & 47\end{array}$

$\begin{array}{lr}\text { Data Collection } & 50\end{array}$

RSMeans Building Construction Cost Data $\quad 50$

$\begin{array}{ll}\text { Definitions } & 51\end{array}$

Measurement Of Energy Consumption (EC) 52

Calculation of Cycle Time (CT) per worker 52

Reduced Energy Consumption (EC) After Adding Workers 53

CHAPTER IV: DATA ANALYSIS

$\begin{array}{ll}\text { Statistical Analyses } & 54\end{array}$

Other Types of Analyses $\quad 55$

Analysis Using Loosely Coupled Multi-Unit System 55

$\begin{array}{ll}\text { Analysis Using System Dynamics } & 58\end{array}$

Analysis Using Discrete Optimization $\quad 61$

Bottleneck Rate of St 3 and when Processing Rate of St $3\left(X_{3}\right)<$ Processing Rate of St $2\left(\mathrm{X}_{2}\right) \quad 62$

$\begin{array}{ll}\text { Findings and Results } & 65\end{array}$

CHAPTER V: SUMMARY, CONCLUSION AND RECOMMENDATIONS 67 


\section{TABLES}

Table

Page

1. Drivers and Barriers of Off-site Production 12

2. Sigma Performance Level 20

3. Comparative Views in Inventory Management 26

4. Tasks, Crew and Labor Information of One Sample 51

5. Results of t-Test $\quad 54$

6. Schedule of a Room Module 56 


\section{FIGURES}

Figure

Page

1. The flow model of production 18

2. Process in various sigma levels $\quad 22$

3. Lean project delivery system 25

4. Future value stream map $\quad 28$

5. Potential causes of defective welds 30

6. Solutions to reduce wind impact 31

7. Solutions to improve welder performance 32

$\begin{array}{ll}\text { 8. Research process of this study } & 37\end{array}$

9. Current VSM to identify factors that waste energy 38

10. System dynamics model of energy consumption 40

11. Potential causes of longer cycle time (using six sigma methodology) 41

12. Modular construction as a loosely coupled system 42

13. Dormitory project 46

14. Floor plan view of a dormitory project and module room 46

15. Discrete optimization based on Little's Law 49

16. Energy consumption of station \#1 59

17. Energy consumption of station \#2 59

18. Energy consumption of station \#3 60

19. Energy consumption of station \#4 60

20. Current situation of energy consumption 61 
21. Future scenario of energy consumption after adding 1 worker at St 3

22. Future scenario of energy consumption after adding 2 workers at St 3

23. Future scenario of energy consumption after adding 3 workers at St 3 


\section{CHAPTER I: INTRODUCTION}

The construction industry contributed $3.7 \%$ to the United States' Gross Domestic Product (GDP) in 2014 (U.S. Department of Commerce 2016). Moreover, the U.S. had over 9 million workers employed in the construction industry (U.S. Census Bureau 2010). One conspicuous feature of the construction industry is that it produced an abundance of waste while consumed vast quantities of resources and energy. According to the U.S Environmental Protection Agency, in 2013, 530 million tons of construction and demolition (C\&D) debris were generated (The U.S Environmental Protection Agency, 2015). In the same year, according to Environmental Protection Agency, 162.2 million tons of C\&D debris were generated from buildings (DuceRomero, 2016). In addition, money, time and resources are wasted when construction projects are poorly managed (Modular Building Institute, 2010). Improving the efficiency of production and management of construction projects can result in savings related to resources, energy, and cost.

It has been estimated that 1-1.2 million dollars per project can be lost in construction industry on waste due to over production, poor handling, incorrect storage, incorrect ordering, design change, manufacturing defects and rework (Dajadian \& Koch, 2014). The associated losses amounted to $\$ 17$ to $\$ 36$ billion per year due to the lack of interoperability (Ahmed \& Forbes, 2010). To improve the efficiency of the capital facilities sector of the construction industry, the National Research Council (NRC) Committee chose the following five breakthroughs from among dozens of potential ideas, concepts, processes and practices, as the methods potentially having the most significant impact on the construction industry efficiency and productivity (Modular Building Institute, 2010). 
1) Widespread deployment and use of interoperable technology applications, also called Building Information Modeling (BIM);

2) Improved job-site efficiency through more effective interfacing of people, processes, materials, equipment, and information. According to the 2009 report of National Research Council (NRC), the job sites for large construction projects are dynamic places, involving numerous contractors, subcontractors, tradespeople and laborers, all of whom require equipment, materials and supplies to complete their tasks. NRC (2009) suggested better use of automated equipment and information technologies as improvements to the efficiencies of the projects.

3) Greater use of prefabrication, preassembly, modularization, and off-site fabrication techniques and processes;

4) Innovative, widespread use of demonstration installations; and

5) Effective performance measurement to drive efficiency and support innovation.

Construction, M., H. (2010) suggested to use modular construction for prefabrication, preassembly, modularization, and off-site fabrication techniques and processes to reduce waste of materials and energy. Modular Construction is a process in which a building is constructed off-site, under controlled plant conditions, using the same materials and design to the same codes and standards as conventionally built facilities-but in about half the time (Modular Building Institute, 2010). Buildings produced in "modules" and installed together on site reflect the identical design intents and specifications of even the most sophisticated site-built facility, without compromises.

Documented benefits of off-site construction versus traditional on-site construction include the following items (Rogan, Lawson \& Bates-Brkljac, 2000): 
- Faster Construction time

- Lower capital costs

- Reduced material waste

- Improved quality

- Better predictability

Because of these benefits, the demand for modular construction has been on the rise. For example, modular hotel construction in the U.S. increased by $25.7 \%$ and $31 \%$ in 2013 and 2014 respectively (Modular Building Institute, 2015). Although the price of energy in U.S. is relatively low, the increased demand of modular fabrication and construction caused an increase in energy consumption, which is an essential component of the production and operating costs.. Therefore, the production growth of modular construction made the need for efficient energy consumption a priority. Though modular construction has many benefits, it has some limitations too. Some of the limitations are following (Belina, 2016):

- Limited design options: Limited amount of material options and home layout possibilities.

- Reduced resell value: There is a stigma that modular homes are of lower quality.

- Difficult to finance: Banks are usually unfamiliar with modular home construction processes.

Modular construction has been used in different kinds of projects such as education, housing, health care, office, government, dormitory, retail and hospitality (Smith, 2014). A housing project of 7-story building for Manchester University, UK, was constructed with a primary steel frame and a two-story podium (Jellen \& Memari, 2013). The first story of the building was constructed below grade for parking. The second story (ground floor) had retails 
space. The remainder of the stories contained modular student housing units. The prefabricated overwater bungalow was made of light gauge steel frame system and wooden panels in China (Wei \& Voellm, 2016). The indoor area of the bungalows ranged from 50 to 100 square meters with one kitchen and different numbers of bathrooms. As the first U.S. hospital implementing modular construction extensively, the Dayton Hospital in Ohio included patient rooms, exam rooms, single-toilet rooms, and patient-unit overhead utilities. They were all built at assembly warehouses just miles from the site and then erected on-site (Bennett, 2014). The modular units worked exceptionally well with the hospital's repetitive design, which incorporated 178 identical rooms on five identical floors. Similar to healthcare buildings, dormitories and school projects had features that were well-suited for prefabrication/modularization (Construction, 2010). The projects of dorms and classrooms using modular construction technology benefited from faster construction schedules. A four-story student-housing complex of 80,000 square feet near Temple University was completed in 2010 using modular construction. The developers said that the $\$ 9.5-$ million project would have costed 25\% more and taken at least 15 months to build instead of 8 months, had it been done on site (Silver, 2011).

In modular construction, the sequence of activities could be different from the corresponding regular construction projects. Researchers paid attention to the differences between modular construction and regular construction. For example, Schoenborn, M., J. (2012) focused on design quality of modular buildings in order to improve production efficiency and worker safety. Campbell (2013) focused on sustainable workflows for permanent modular wood construction. Permanent modular construction is a type of delivery method where a large portion of a building is prefabricated as modules in a controlled environment. It was suggested in that research that greater integration between designers and implementation teams leads to more 
sustainable production. According to the National Science and Technology Council (NSTC, 2008) report, construction's portion of the GDP would increase 10 percent if the equipment, furnishings and energy required to complete buildings were included. However, in this research, the author will focus on reducing the cycle time of the operation to make modular construction more energy efficient. The author implemented Value Stream Mapping (VSM) to generate and review the process in order to minimize the non-value added activities and energy use. Lean analysis often does not suggest an actual method to reduce or eliminate the variations in the process. Six-Sigma has the potential to fill this gap.

\section{Lean Six Sigma Principles in Modular Construction}

Over the past three decades, the U.S. manufacturing industry made significant progress in increasing productivity and product quality while lowering product lead times and delivery times. In contrast, the U.S. construction industry has seen a decline in both its share of the gross national product and its annual productivity growth rate (Diekmann et al., 2004). The quality of construction has faltered during this period as well. Waje \& Patil (2012) indicated that 6-15\% of construction cost is found to be wasted due to rework of defective components detected late during construction and 5\% of construction cost is wasted due to rework of defective components detected during maintenance. On the other hand, manufacturing industries achieved success by eliminating the waste and improving the quality (Wilson, 2010), improving

productivity and reducing cycle time (Kwaka \& Anbari, 2006; Snee, 2010; Wilson, 2010). Early studies suggested that lean improvements can reduce the time required to set and finish modular housing on the construction site (Mullens, 2004).

Due to an increased focus on production cycle times and quality, the U.S. manufacturing industries experienced an increase in quality, flexibility and productivity, while also managing to 
lower production lead times and the cost of production and delivery times (Schonberger, 1996). Subsequently, manufacturing management saw a shift from conventional practices of planning and control, to a focus on interactive sets of principles aimed at achieving and facilitating improvements, such as lower cycle times.

The visible success of lean principles in the automobile and manufacturing industries generally prompted other industries to adapt and apply these concepts to achieve similar benefits. Lean manufacturing mainly reduced waste. It could not eliminate or reduce variations in manufacturing processes. The application of Six Sigma helped in identifying variations. In this case, Six Sigma is a supplement to lean method.

In the pursuit of productivity improvement, it is important to ensure the quality of work processes to enhance the overall reliability and stability of construction operations. There are several construction productivity improvement principles such as lean production, just-in-time (JIT), rapid machinery changeovers, pull scheduling, last planner, etc. (Thomas et al. 2003). However, most of them are not quantitative or practical methods or metrics for assessing the defect rates of construction operations. The defect rates in construction processes are largely caused by unreliable workflow when sources of process variability are involved (Tommelein 2000; Hopp and Spearman 2000; Howell et al. 2001; Thomas et al. 2002). The lean principle attempts to address the effect of variability, but not to eliminate or reduce variability by removing the root causes entirely (Abdelhamid 2003). In order to estimate the defect rates involved in construction operations in a more quantitative and organized way, this research applies both lean and Six Sigma principles. 


\section{Aim of the Thesis and Research Question}

The purpose of this study is to identify the non-value adding tasks based on cycle time

analysis and possible causes of wasted cycle time in order to make the energy consumption process of modular construction more efficient. The research question and hypotheses were developed through a review of relevant literature. Limitations and delimitations discussed below clearly specified the boundaries of this study. The research question and research hypothesis examined in the study are given below.

The research question was whether the application of Lean Six Sigma can reduce the energy consumption of modular construction. In order to answer that question, the first objective of this research was to identify the principal components of production effectiveness in modular construction. The second objective was to explore whether the relationship between these components and energy efficiency is modified by the implementation of Value Stream Mapping technique. The author predicted that if Value Stream Mapping data impacts energy consumption, there should be an interaction between the principal components of production effectiveness and energy efficiency. For terminology definitions, see Appendix A.

\section{Significance of the Study}

The objective of this study is to build a framework through the implementation of Lean analysis and Six Sigma in modular construction and to measure its impacts on reduction of energy consumption. While theoretical evidence abounds to support the perceived benefits of Lean Six Sigma methods, very little empirical work has been done to quantify its actual use and the associated costs and benefits in the modular construction industry. Construction researchers overlooked an important range of critical opinions pertaining to the energy consumption of module production in the construction process and the possibility of lean Six Sigma in the 
production. Lean construction, which is independent of commercially vested interests, needs an empirical research (Green, 1999).

The following example shows how energy might be wasted in modular construction. Suppose a company has 4 stations running concurrently to produce a module, which must complete 4 tasks in 4 stations in a sequential order. The equipment energy consumptions per hour at stations 1, 2, 3 and 4 are $100 \mathrm{KW} / \mathrm{hr}$., $150 \mathrm{KW} / \mathrm{hr} ., 250 \mathrm{KW} / \mathrm{hr}$. and $200 \mathrm{KW} / \mathrm{hr}$. respectively. The energy consumptions of the stations depend on the amount of time spent for completing the tasks. If a product defect is found at station \#2 for example, workers need to spend extra time to fix it, which will exceed the planned production time and therefore increase the energy consumption of station \#2. Moreover, tasks of station \#1 will have to wait until the problem of station \#2 is fixed because the resources of labor and equipment are still occupied by station \#2. This leads to additional energy usage since the equipment keeps running. To solve this problem and to reduce the energy consumption, workers from other stations (i.e. who are standing idle or doing nothing) will move to station \#2 where task \#2 and the unfinished tasks of station \#1 are being completed. This will increase the processing rate. By increasing the processing rate, more work will be done in less time, which will consequently reduce the energy consumption.

According to a recent study by the U.S. Energy Information Administration (EIA, 2016), a total of 39 quads of energy were consumed by the building sector in U.S. in 2015. Of the 39 quads, homes accounted for $54 \%$ and commercial buildings accounted for $46 \%$. Meanwhile, very few studies and empirical work have been carried out in the aspect of optimization of energy in modular construction. The research contributions of this study include the following items: 1) 
quantitative methods to identify the current investigatory themes, and (2) optimization of production configuration in modular construction.

\section{Assumptions}

There is a strong relationship between the implementation of Lean Six Sigma and reduction of energy consumption in modular construction. Over the past years, energy expenses of the industries have been higher due to higher defects, longer cycle time in production and lack of proper production planning. Because of not taking advantage of already proven techniques, as opposed to be taken by manufacturing industries, following the trend of manufacturing industries of implementing the Lean Six Sigma should have an impact on reducing energy expenses.

\section{Hypotheses and Limitations}

Ho: Application of Lean and Six Sigma cannot reduce the energy consumption in modular construction

H1: Application of Lean and Six Sigma can reduce the energy consumption in modular construction

The focus of the research was on modular construction for the implementation of Lean Six Sigma to improve energy efficiency. One limitation is due to the varieties of activities carried out by the modular construction industry. The author reviewed published literature, studied different cases, visited modular-construction companies, and interviewed with industry representatives to collect data and build the measurement framework of energy efficiency in modular construction. The author also used national surveyed data and considered variations of equipment units. Particularly, these limitations were overcome by making realistic assumptions based on the RSMeans Cost Data Book for the Construction Industry in the U.S. 
There might be tremendous differences in the configurations of modular production. The author designed and configured a residential building and considered many possible and practical Work-Break-Down (WBD) structures for that type of building.

The contents of this thesis are organized as follows: Chapter 1 is about modular construction, its advantages and disadvantages, application of Lean Six Sigma in modular construction and the overall purpose of this thesis. Chapter 2 is about the previous contributions of Value Stream Mapping and System Dynamics in Modular Construction.

Chapter 3 is about the design of the methodology. It discusses how data would be collected and used to validate the model. Chapter 4 is about the analysis of the data collected and actual findings. Chapter 5 is about the summarization of the data presented earlier. The conclusion articulates the main points of this research with clarity and makes recommendation for further research. 


\section{CHAPTER II: LITERATURE REVIEW}

\section{Modular Construction}

Modular construction is also called off-site construction or production. The roots of the modular construction stem from the end of World War I when the construction industry had major shortages of skilled labor and building materials. This shortage triggered a search for new methods of construction that would mitigate the problem. By the end of World War II traditional building operations needed to expend the industrial capacity. These efforts stimulated the shift in the industry from traditional techniques towards off-site technologies (Taylor, 2009). Pan et al. (2012) defined Off-Site Production (OSP) as the manufacture and preassembly of building components, elements, or modules before installation into their final locations. The recent research on the benefits of OSP indicated that, compared to traditional methods, the implementation of OSP had the benefits of reduction in (1) time, (2) defects, (3) risks, (4) costs, and (5) environmental impact. The consequent increases included: (1) quality, (2) consistency, (3) predictability, (4) productivity, (5) performance, and (6) profitability (Goodier and Gibb, 2005; Blismass and Wakefield, 2009; Pan et al. 2012). Pan et al. (2005; 2012) highlighted the low levels of OSP uptake despite of the demand of higher implementation of such technology by house builders. The main driver for off-site manufacturing was the shortage of skilled labor. However, the main barrier was the worry of high capital costs of implementing such technology perceived by the industry (Pan et al. 2005; 2012).

The reasons for the low uptake of OSP in the construction industry included the following items: (1) the difficulty to ascertain the benefits, (2) the negative image regarding prefabricated/modular homes, (3) poor quality, (4) poor aesthetics, (5) lower choice, and (6) 
previous failures (Nadim and Goulding, 2010). Table 1 lists the drivers and barriers discussed by researchers (Pan et al. 2005).

Table 1

Drivers and Barriers of Off-Site Production.

\begin{tabular}{ll}
\hline \multicolumn{1}{c}{ Drivers } & \multicolumn{1}{c}{ Barriers } \\
\hline Addressing the skill shortages & Higher capital cost \\
Ensuring time and cost certainty & Difficult to achieve economies of scale \\
Achieving high quality & Complex interfacing between systems \\
Minimizing on-site duration & Unable to freeze the design early on \\
\hline
\end{tabular}

According to Walden (2016), Simultaneous site development and building construction at the plant makes project 30-50\% sooner than the traditional building method. Velamati (2012) addressed the potential impact of high rise modular construction that could inure time and financial savings. Transferring site-based construction activities to factory environments is a tangible way of helping to overcome the industry's shortage of skills (Southern, 2016).

McDonald (2015) sited one of the barriers of prefabrication is that teams design the project and look to the prefabricated elements, which limits prefabrication potential and creates suboptimal designs. Though it is very well understood that modular construction can save time and cost, very few researches were conducted about how to reduce the energy use. Therefore, this research will focus on that area, which will ultimately reduce the overall cost as well.

\section{Lean Six Sigma}

The study of cycle time and takt time started with the shifting process from large-scale mass production, to more agile, customer-focused production in the U.S. (Womack et al., 1990). This process was pioneered by the late Henry Ford. Womack et al. (1990) observed the diffusion of highly successful production and management system named "lean production" in the last 30 years. The impetus for lean production occurred when Toyota caught up with the production 
level of automobile in America in three years in post-World War II (OHNO 1988; Hopp1996). Back then, limited supply of raw materials and inadequate space for inventory in Japan fostered the atmosphere in favor of such concepts as just-in-time (JIT) management and zero inventory. The features of Ford's automobile production at that time included: (1) only the workers on the assembly lines were adding values to the processes. (2) The emphasis was placed on continually running the production line. This common practice was thought to be justified by the expense of purchasing such equipment. This practice appeared to build up errors, which they could not afford. Toyota then made the strategic decision to focus the manufacturing efforts not on massive volumes of a product, but on many different products in smaller volumes. Thus, it greatly reduced the carrying costs required for huge inventories, rework and production time.

Lean was a business strategy with the primary objective to eliminate waste, which was defined as "anything that does not add value" (Aziz and Hafez, 2013). In lean strategy, customers defined value. Value-added activities are the ones that customers were willing to pay for, the ones that helped transform the product or service in some way, and the ones that must be done correctly the first time (Banawi, 2013). Lean construction principles contributed to sustainable construction and touted as a means which could not only optimizing construction costs, but also reduce construction waste and its attendant impact on environment (Koskela et al, 2002).

There were 7 different forms of waste (Ohno, 1990), including:

1) Transport: Unnecessary move of products or materials around is a waste; because the more frequently things are moved, the more chances damages could occur. This situation could happen to modular construction as well. Modules are often needed to be 
transported from an off-site location to a jobsite for installation purposes. But needless trips when transporting modules cause energy wastage.

2) Waiting: Waiting in any form is a waste. In modular construction, equipment consumes energy in waiting time, which is a waste.

3) Overproduction: Producing more than what customers need is a waste. Overproduction causes surplus inventory cost, materials consumption, and labor usage. In modular construction, sometimes, appropriate overproduction helps to meet uncertain demand. Nevertheless, overproduction leads to an energy wastage, because equipment needs to run for extra time and it reduces equipment efficiency.

4) Defect: Any process that fails to transfer inputs to desired outputs is considered as a waste. Similarly, failure to meet customer's requirements is considered as a waste. In modular construction, rework due to defects can lead to an energy wastage because the process of disassembly, repair, and reassembly consumes energy.

5) Inventory: Inventory is usually considered as a non-value adding commodity, even though it may be requisite. The possible risks of having inventories are the damage, obsolescence, spoilage, and quality issues to commodity. In modular construction, too much inventory can lead to an energy wastage due to heating, lighting and cooling of the space to store the inventory.

6) Motion: Any physical movement by people that does not add value to a process is waste, including moving things, walking, lifting, etc. In modular construction, workers might move to do non-value adding tasks, which wastes energy because equipment continues running. 
7) Extra Processing: Any processing that does not add value to a product is a waste. In modular construction, additional processing leads to extra running of equipment, which consumes energy inefficiently.

\section{Lean Principles}

Lean principles have been used in different industries. For instance, software, aerospace, air travel and shipbuilding industries all had extensive efforts directed at applying lean principles to improve profitability, quality and reduce waste (Diekmann, Balonick, Stewart \& Won, 2004). The architecture, engineering and construction (AEC) industries started the applications of the innovative ideas about lean thinking to their businesses. An example of lean implementation in AEC industries was demonstrated by $\operatorname{KOSKELA}(1992,2000)$, who originated the idea that construction processes were systems of transformations, flows and value (TFV) adding actions, a.k.a. TFV model. BERTELSEN (2002) expanded the lean manufacturing model to include the ideas of construction as one-of-a-kind production, construction as a complex system and construction as cooperation. In the United Kingdom, the Construction Task Force produced "Rethinking Construction" (The Egan Report) that applied lean principles to the construction sector in the United Kingdom (The Report of the Construction Task Force, 1998). The following listed principles were crucial to lean production to meet the increasing demand of the construction industry and reduce costs (Koskela, 1992).

- Meeting the Requirements of the Customer: Attention must be paid to quality defined by the requirements of the customer. The success of production hinged on the satisfaction of the customer. A practical approach to this was to define customers for each stage and analyze their requirements. 
- Reducing Non-Value Adding Activities: Non-value adding activities generally resulted from one of three sources:

a) The structure of the production system, which determined the physical flow that was traversed by material and information;

b) The manner in which the production system was controlled;

c) The nature of the production system such as defects, machine breakdowns and accidents.

- Reducing Cycle Time: Cycle time was the total time required for a piece of material to traverse the production flow. Cycle time could be calculated using Equation 1 shown below:

Cycle Time $=$ Processing Time + Inspection Time + Wait Time + Move Time .

This research identified the following activities to reduce cycle time:

Eliminating Work in Process (WIP).

a) Reducing batch sizes;

b) Changing plant layout to minimize moving distances;

c) Keeping things moving to smoothen and synchronize flows;

d) Reducing variability;

e) Isolating main and value-adding sequence from supportive or secondary work;

f) Changing the processing order of activities from sequential to parallel;

g) Solving problems caused by the constraints, which slowed down material flow.

- Reducing Variability of activity duration: Variability of activity durations increases the volume of non-value adding activities. For example, queuing theory demonstrates that variability increases cycle time (Koskela, 1992). Reducing variability helps to solve nonconformance of products and increase consistency in work durations of both value adding 
and non-value adding activities. A few strategies aimed at variability reduction are listed as follows (Koskela, 1992):

a) Standardization of activities by implementing standard procedures.

b) Mistake-proofing devices.

- Increasing Flexibility: This lean principle focused on increasing the ability of the production line to meet the demands of the marketplace and changes. Research recognized the following activities aimed at increasing output flexibility (Stalk, 1990):

a) Minimizing lot sizes to match demand closely;

b) Reducing the difficulty of setups and changeovers;

c) Customizing as late in the process as possible;

d) Training a multi-skilled workforce.

- Increasing Transparency: This lean principle focused on making the entire operation flow visible and comprehensible to the people involved in the process so that mistakes could be located and solved quickly.

\section{Application of Lean in Construction Industry}

The application of lean principles to the construction industry is known as lean construction. Construction practitioners argued that construction was distinct from auto manufacturing and that lean principles were not applicable (Diekmann et al, 2004). In addition, highly customized building design made most buildings one-of a-kind products. Nevertheless, under the conditions of low market demand, manufacturing companies usually promoted the production of small quantities with many varieties. This strategy became the major driver of lean production in the construction company. Similar to automobiles, a building module is made of 
many components and the number of processes involved is immense. This similarity sets the foundation for the application of lean principles in modular construction.

Koskela (1992) studied the adaption of the lean production concepts to the construction industry. He challenged the implementation of lean production philosophy within the construction industry and presented an initial set of principles as implementation guidelines to create flow processes in construction. Koskela (1992) further argued that lean construction consisted of a series of flow-conversion activities. Conversion activities were those operations performed to add values to materials. Conversion could also transform information into a product and flow, including such tasks as inspections, waiting, moving and storing (Harris \& McCaffer, 1997). Fig. 1 shows a flow model of production (Koskela, 1992), in which moving, waiting, processing, and inspection are all part of a value stream. The results of inspection include rework, move on to next process, or scrap.

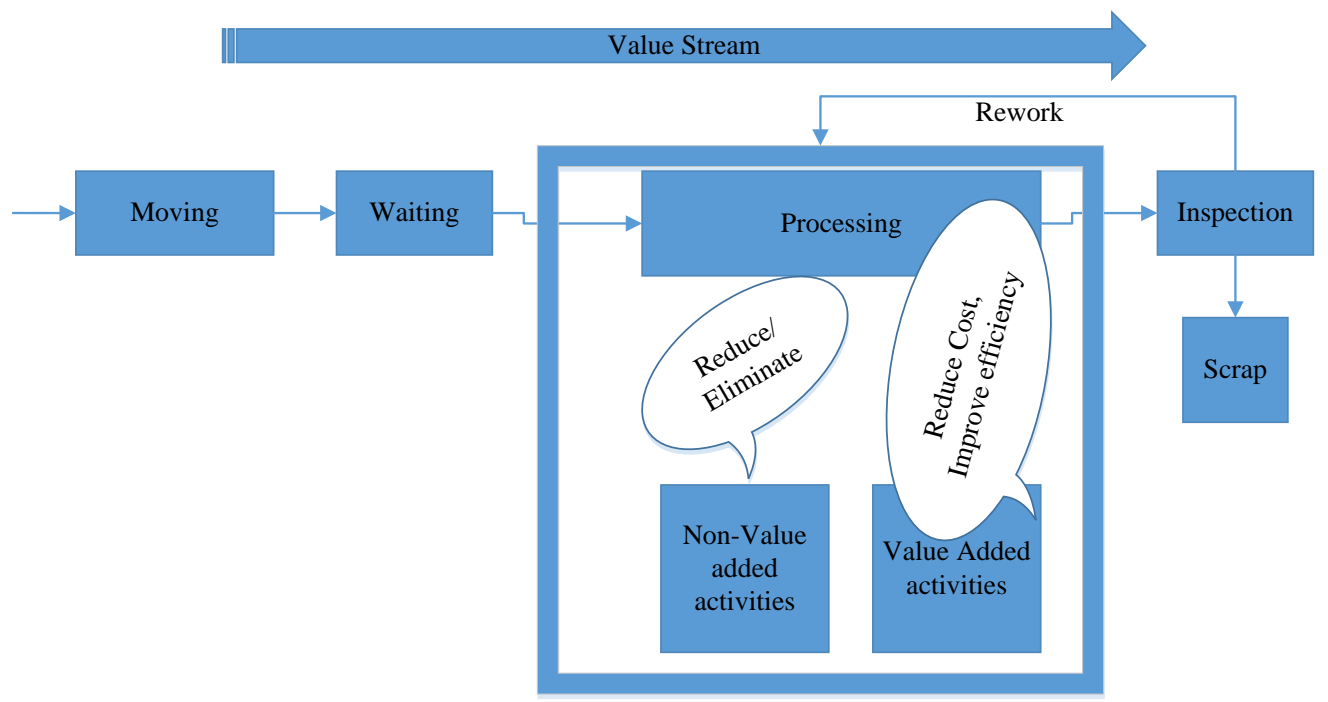

Figure 1. Flow model of production 
The lean construction system sees production as a flow of material, information, equipment and labor from the raw materials to the product (Koskela, 1992). This flow also includes conversion, inspection, waiting or moving steps as shown in Fig. 1. Processing represents the conversion aspects of production. Inspecting, moving and waiting represent the flow aspects of production (Koskela, 1992). Waste in a construction process affects worker's productivity. According to Koskela (1992), lean construction includes: practice of JIT, use of pull-driven scheduling, reduction of variability in labor productivity, improvement of flow reliability, elimination of waste, simplification of the operation and implementation of benchmarking. In general, lean construction focuses on speed and helps to reduce waste in time. Lean method cannot reduce variations in construction process without the application of Six Sigma technique, which is a quality tool that emphasizes on the reduction of the number of errors in a process.

\section{Key Principles of Six Sigma}

Six Sigma principle was an effective and statistical-based methodology in measuring defect rates to maintain a high-standard quality level. Bill Smith originated the Six Sigma concept in 1986 to address Motorola's lack of manufacturing quality (Banawi, 2013). It gained popularity in 1995 after Jack Welch, the Chief Executive Officer of General Electric, implemented Six Sigma to improve the quality of General Electric's general manufacturing processes (Banawi, 2013). The status of the companies changed after the application of the SixSigma methods to their businesses. Motorola accumulated savings from 1987 to 1997 for a total of $\$ 14$ billion. By the end of 1998 , GE had accumulated $\$ 750$ million in sales, which grew to $\$ 1.5$ billion by the end of 1999 (Banawi, 2013). 
The aim of Six Sigma method was to improve the quality near perfection, which means 3.4 defects per million opportunities (DPMO), to maximize the customer satisfaction and business benefits $(\mathrm{R}, 2014)$. Table 2 explains the different levels of Six Sigma and the associated DPMO (Weltman \& Swink, 2016).

Table 2

Sigma Performance Level

\begin{tabular}{cccc}
\hline & Six Sigma Level & \% Accuracy & DPMO \\
\cline { 2 - 4 } Virtual Perfection & 6 & $99.9997 \%$ & 3.4 \\
Good & 5 & $99.98 \%$ & 233 \\
& 4 & $99.4 \%$ & 6210 \\
Improvement Needed & 3.5 & $97.7 \%$ & 22700 \\
& 3 & $93.3 \%$ & 66807 \\
\hline
\end{tabular}

Some of the key benefits of Six-Sigma method are listed below (Panneerselvam, 2012):

- It ensures enhanced product quality.

- It enables predictable delivery of the products

- It helps to achieve productivity improvement.

- It helps to have rapid response to the changing needs of customers

- It also facilitates the development and introduction of new products into market place.

After realizing the huge benefits of it, since the late 1990s many companies adopted Six Sigma as part of their management strategies, including Honeywell, ASEA Brown Boveri, Black 
\& Decker, Bombardier, Dupont, Dow Chemical, Federal Express, Johnson \& Johnson, Kodak, Navistar, Polaroid, Sony, Toshiba, etc. (Pande, Neuman et al. 2000). The main purpose of adopting the Six Sigma was to achieve customer satisfaction. Customer satisfaction could be achieved through high quality products or low-defect products. Traditionally, defects were products containing flaws in a manufacturing process, customer dissatisfaction in a service department, or documentation errors in an office. Lindermann et al. (2003) stated that Six Sigma principle relied on scientific methods to make significant reductions in customer-defined defect rates or to eliminate defects from every product, process, and transaction. DPMO measures defect possibility, which indicates how many defects would arise if there were one million opportunities.

$$
\begin{gathered}
\text { DPMO }=\frac{\text { Total number of defects in the sample }}{\text { Total number of defect opportunities in the sample }} \times 1000000 \\
=\frac{\text { Total number of defects in the sample }}{\text { Sample Size } \times \text { Number of defect opportunities per unit in the sample }} \times 1000000
\end{gathered}
$$

Six Sigma principle can be represented by a normally distributed curve for product quality distribution. The mean is located at the center of the normal distribution curve and the lower and upper limits are six times of the standard deviation (a.k.a. sigma) from the centerline. In other words, the range of the lower or upper limit of defects is \pm 6 sigma from the mean. Equation 2 calculates how many standard deviations (sigma) can fit between the mean. The specification limit can be found from a sigma value or Z-score. Low Z-score means that a significant part of the tail of the distribution extends past the specification limit. So, the higher the sigma (Z) score, the fewer the defects. Fig. 2 shows various curves of normal distributions. If a curve has a high $\mathrm{Z}$ score, it will show a centered and narrow $6 \boldsymbol{\sigma}$ curve. For a low $\mathrm{Z}$ score, it shows a distributed and wide $6 \sigma$ curve. 


$$
\mathrm{Z}=\frac{|S L-\overline{\mathrm{x}}|}{\sigma}
$$

$$
\begin{aligned}
& \text { SL=Specification limit } \\
& \overline{\mathrm{x}}=\text { Mean } \\
& \boldsymbol{\sigma}=\text { Standard deviation }
\end{aligned}
$$

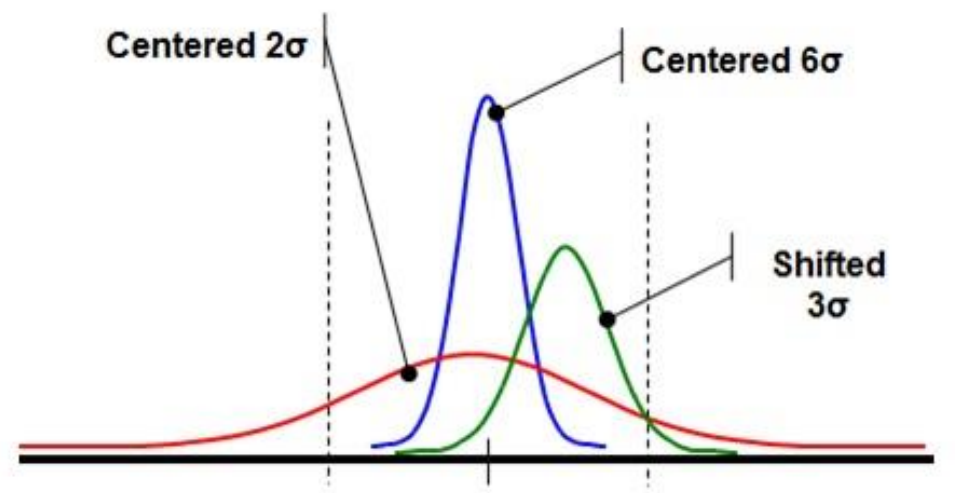

Figure 2. Process in various sigma levels

Ultimately, Six Sigma principle aims to keep the defect rates under 0.002 parts per million (ppm). If a data set falls within \pm 3 sigma from the mean (of the upper and lower specification limits), it represents a 2,700 ppm (0.27\%) defect rate. That is considerably larger than 0.002 ppm. Specifically, assuming that the ideal mean is moved up to \pm 1.5 sigma, it adjusts the defect rate into $3.4 \mathrm{ppm}$ within the quality level of \pm 6 sigma. It signifies only $3.4 \mathrm{defects} / \mathrm{million}$ parts or operations. Motorola used it (3.4 ppm) as the target level when implementing Six Sigma principle (Lindermann et al. 2003). While the $3.4 \mathrm{ppm}$ defect rate might be an inappropriate goal for construction operations, the fundamental concept of taking Six Sigma principle would still be 
applicable. Its statistical definition is to minimize the defect rates along with different sigma levels. The continuous pursuit of performance improvement through proper implementation of Six Sigma principle can be a drastic extension of traditional approaches for achieving a high level of process quality in construction industry. An example of implementing Six Sigma principle in the construction industry is "Define-Measure-Analysis-Improvement-Control" (DMAIC) (Harry and Schroeder 2000; Ahn 2000). Appendix B of this thesis shows the details of DMAIC. Six Sigma is for problem solving. Lean construction, on the other hand, is for process efficiency. The combined application of both lean and Six Sigma could maximize the benefits of these technologies to the industry, especially modular construction.

\section{Combined Application of Lean and Six Sigma in Modular Construction}

By working in unison, Lean and Six Sigma represented a potent framework in eliminating process variation. After combined, lean tools created a set of standards for problem solving and Six Sigma tools investigated and resolved any variation from the set of standards (Breyfogle et al, 2001). From the perspective of waste reduction, lean identified waste and Six Sigma eliminated waste. Moreover, Six Sigma focused on the problems that were hard to find but easy to fix, which were better addressed using lean production tools (Hammer and Goding, 2001).

To guide the implementation of lean construction on project-based production systems, Ballard (2000) developed Lean Project Delivery System (LPDS) as a conceptual framework. LPDS model had 5 main phases, each of which was comprised of three modules. Figure 3 shows the details of LPDS model (Ballard, 2000). The inter-dependence between the phases (e.g. that design of product and process should be performed concurrently) was represented by sharing one module between two subsequent phases. Production control and lean work structuring were both 
shown to extend throughout the 5 main phases. In Figure 3, the number in a circle or an octagon shape represents the phase that the module belongs. The modules with two numbers are shared between two different phases. For example, the module "Product Design" is part of the "Lean Design" and the "Lean Supply" phases. In this framework, modules bounded by octagons are candidates for the DMAIC (Six Sigma) approach because they are existing processes. For example, fabricators can utilize this approach to investigate and improve processes that exceed the allowable tolerances. The doors and frames case study in Tsao et al. (2000) investigated the installation of 510 hollow-metal door frames into the housing buildings of a prison. The purpose of a prison was to keep inmates confined. On this project, it was the creation of walls and doors that brought value to the owners. The involvement of specialists/suppliers in design was advocated by Lean practices. Similarly, circle-shaped modules are candidates for the Design For Six Sigma (DFSS) approach which is most suited for new products or processes or when incremental changes need to be incorporated into existing products or processes.

Another example is on-site assembly or installation processes suffering from variability in performance due to late delivery of material and equipment, design errors, change orders, machine breakdowns, environmental effects, occupational accidents, and poorly designed production systems. The DMAIC approach can help to identify and eliminate the root causes behind these problems. 


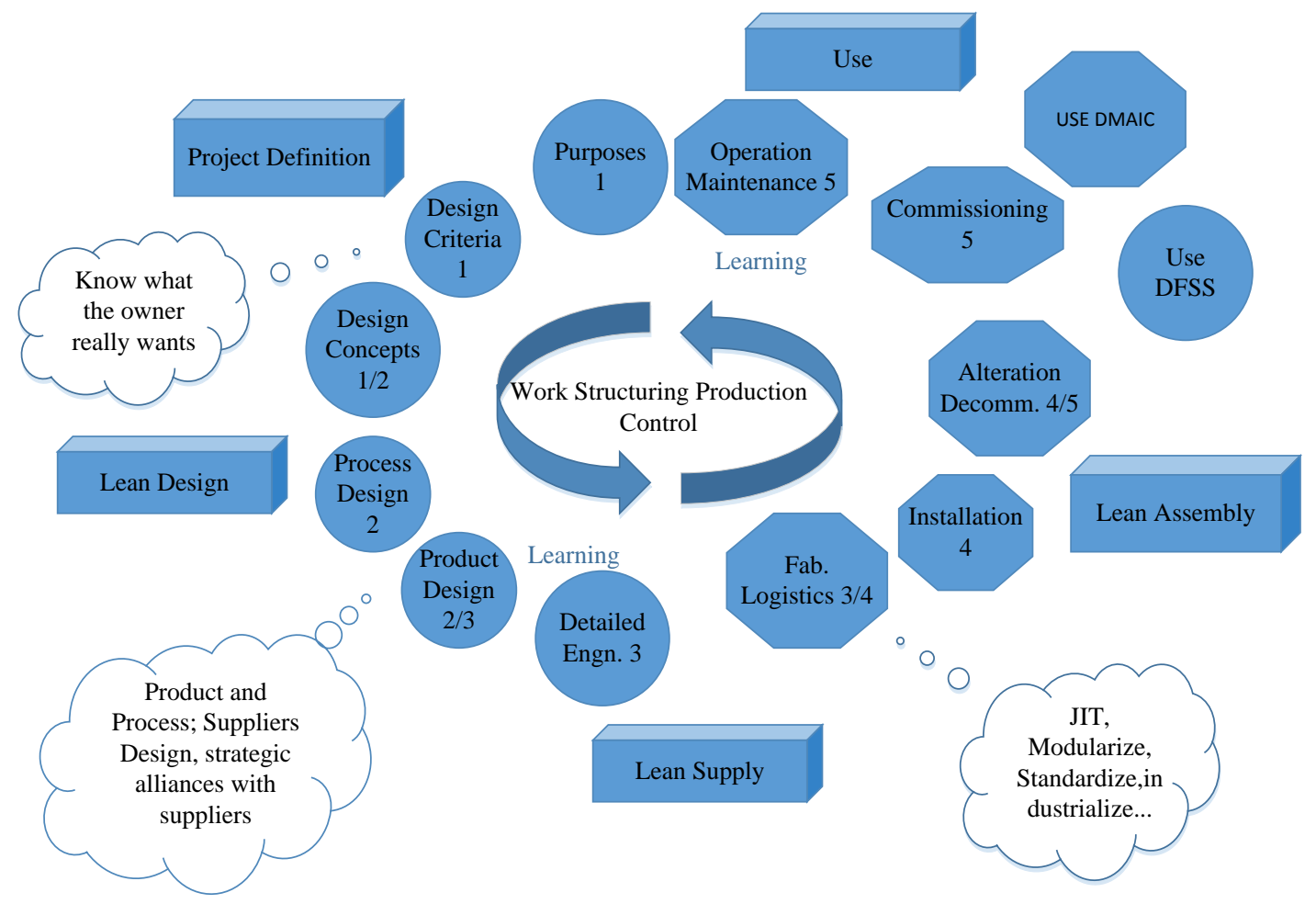

Figure 3. Lean project delivery system.

\section{Value Stream Mapping (VSM)}

Even though lean construction alone provided the idea of viewing production as a flow and led to the principle of removing waste to achieve better workflow, it didn't clearly show the underlying mechanism of how to measure the level of defects in the current work processes (Howell and Ballard, 1994; Howell, 1999). For example, in inventory management, typical lean production or JIT philosophy attempts to attain "near zero inventories" rather than finding an optimal level of inventory (Table 3). Many researchers raised the question about the size of resource buffers to achieve the best performance in a volatile and uncertain construction environment (Ballard and Howell, 1995; Al-Sudairi et al. 1999; Pheng and Chuan, 2001; Sakamoto et al. 2002) 
Table 3

Comparative Views in Inventory Management

\begin{tabular}{lll}
\hline Items & Lean & Six sigma \\
\hline Resource & Near zero resource buffer & Optimum resource buffer for \\
management & & maximum productivity \\
Objectives & & \\
\hline Methods & Minimization of the cost of & Reduction of the total project cost by \\
& redundant resources and & maintaining the optimum resource \\
& increasing the reliability of & buffer and eliminating the loss of \\
& the process through JIT & productivity caused by the resource \\
& technique & shortage \\
\hline Usefulness & Inadequate for the & Adequate for the construction process \\
& construction process which & and useful for a resource management \\
& has many uncertainties and & plan \\
& discontinuous activities & \\
& & \\
& &
\end{tabular}

$\mathrm{Yu}$, et al. (2013) developed and implemented a production system for effective application of lean tools in building components prefabrication. They chose communication shelter production line of Kullman Building Corporate (KBC) as their case study. KBC was a U.S. based, modular building company. They started off with a very common lean technique called 5S (a.k.a. sort, straighten, shine, standardize, and sustain) to show the immediate improvement to the workers and middle managers. Then they implemented future Value Stream Mapping (VSM) method in order to eliminate the root causes of wastes and increase the 
percentage of completion rate of modules. The low completion rate of modules was due to variations of workloads caused by different module configurations.

VSM was a tool demonstrating both value added and non-value added activities in the processes required to bring a product from raw material state into the hands of the customer, bring a customer requirement from order to delivery, and bring a design from concept to launch (Vitasek, 2013). As shown in Fig. 4 below, three measures, including workload-leveling, restructuring work, and in-station quality, were used to increase process reliability and achieve a 6-h takt time. The basic idea of workload leveling was to meet varying customer demand (a mix of modules with variations) without workload fluctuation in the manufacturing process. Workers at each station were assigned based on the configuration of the module at that station. Worker assignment was part of lean production planning. The responsibility of deciding production sequence was moved from sales to production line managers. The purpose of restructuring work was to balance the production line so that the overall cycle time of each station could be as close to the takt time as possible. In 4 months after the implementation of 5S, the labor efficiency was improved by $10 \%$, the labor cost was reduced by $18 \%$, and the overtime was reduced from $20 \%$ to $5 \%$ in the company. 


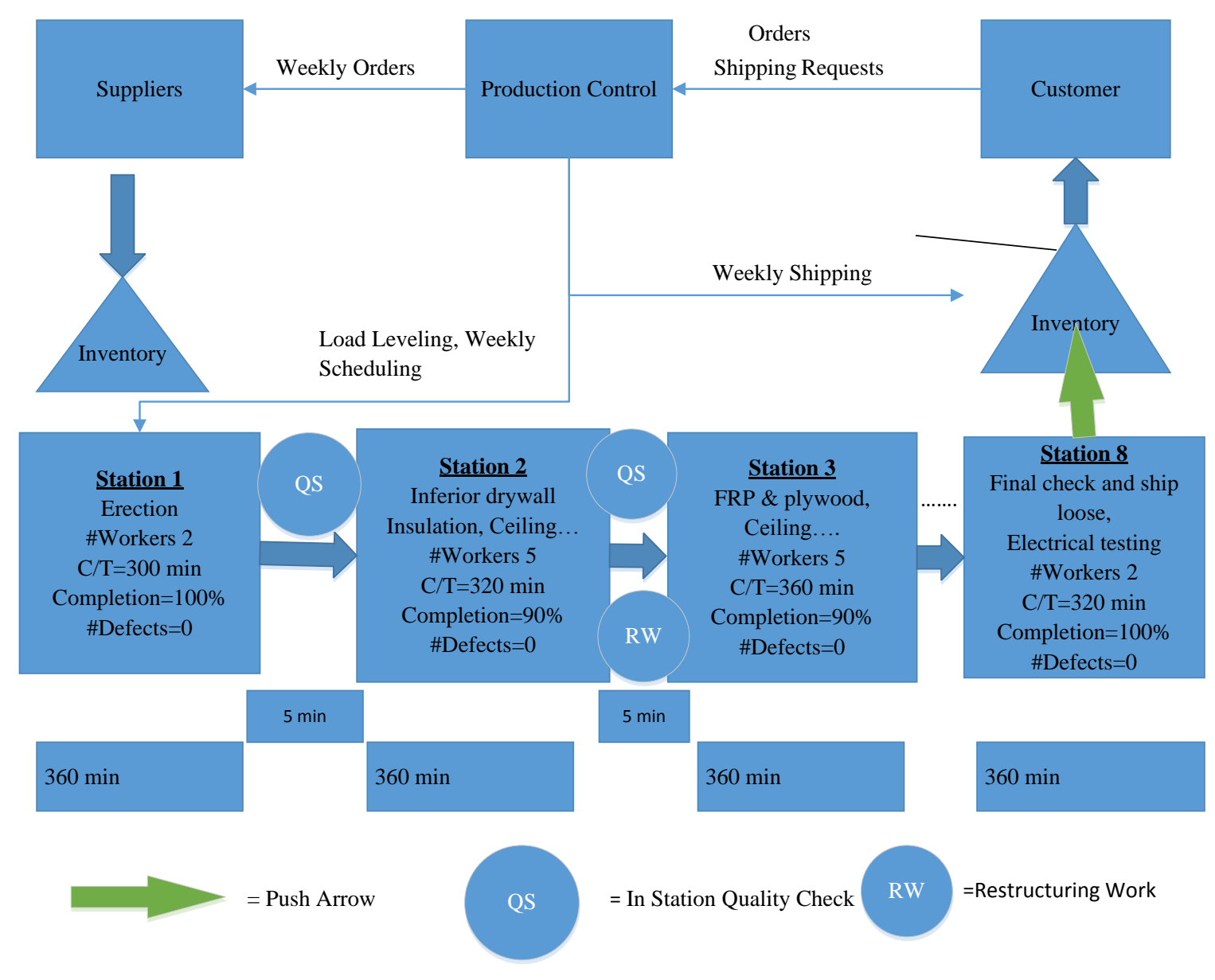

Figure 4. Future value stream map.

Anderson and Kovach (2013) described how a construction company named JV

Industrial Company (JVIC) Ltd applied Lean Six Sigma methodology to reduce welding defects in turnaround projects. Action research method of inquiry involving employees and researchers working together was used following the DMAIC (Define, Measure, Analyze, Improve, and Control) method. The purpose of this Lean Six Sigma project was to solve the welding defects problem. By implementing windshield standards, training welders through Welder University, 
and instituting eyesight tests for welders company-wide, the weld repair rate decreased by more than $25 \%$, which was translated into a savings of $\$ 90,000$ for this company.

Figure 5 below shows the potential causes of defective welds in the process. In this phase the project item identified potential causes of high butt weld repair rates through multiple brainstorming sessions using a five why analysis. Potential root causes included machines, methods, environment, measurements, materials and people. 


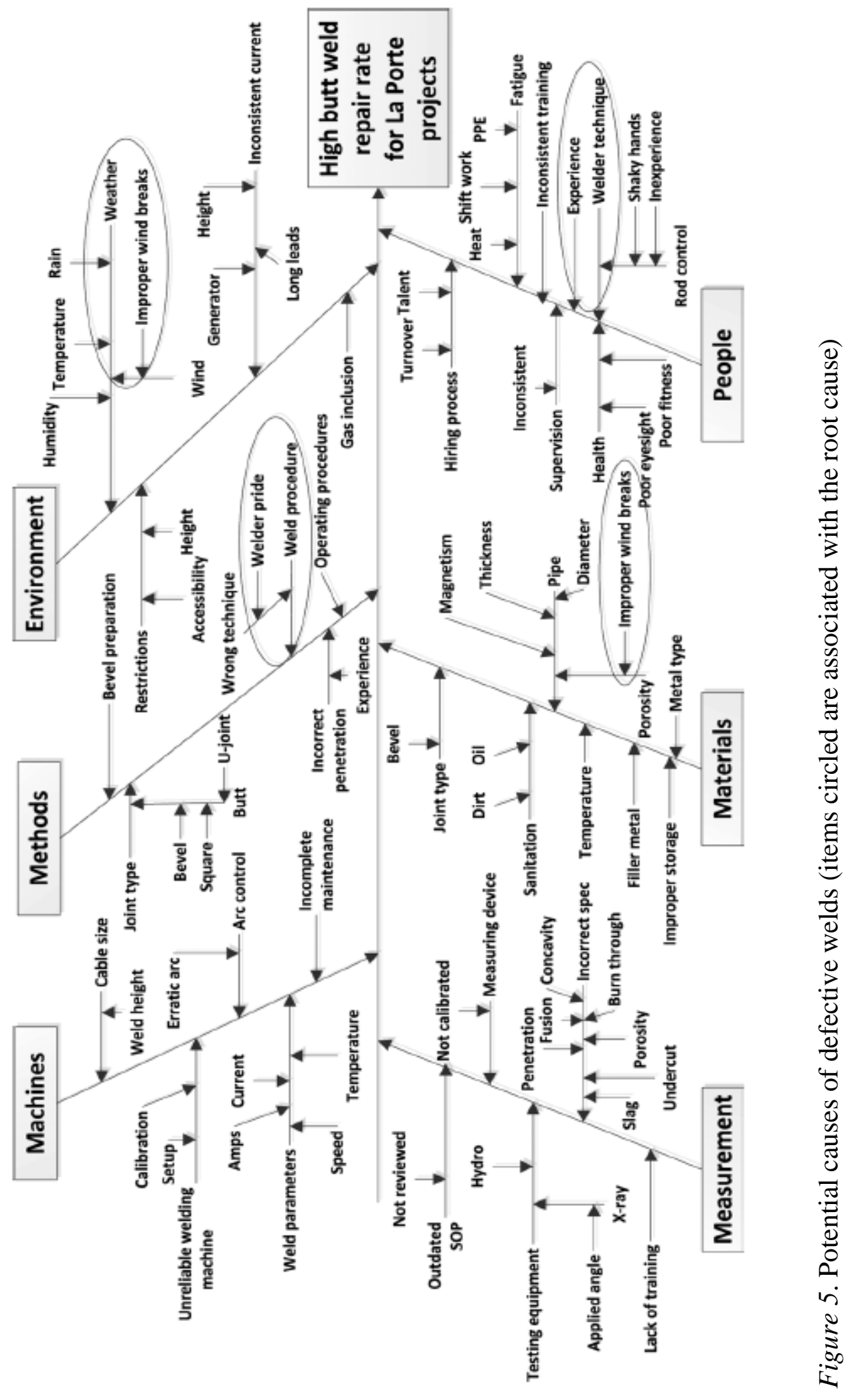


Figure 6 below is the part of the improve phase where it shows potential solutions for the two root causes of defective welds through brainstorming sessions. Soultions options are then evaluated using 1,3,9 scale where 1 represents that the solution option does not fulfill the desired characteristic very well and 9 represents that the solutions option does fulfill the desired charcteristic. To reduce wind impact on the welding process, inspecting wind shields ( C ) is the highest rated soultions.

\begin{tabular}{|c|c|c|c|c|c|}
\hline \multirow[t]{2}{*}{ Desired Characteristics } & \multicolumn{5}{|c|}{ Solutions Options (Ways to reduce wind impact on Welding } \\
\hline & $\begin{array}{c}\text { A. } \\
\text { Secure } \\
\text { Load }\end{array}$ & $\begin{array}{l}\text { B. Design } \\
\text { Better } \\
\text { Wind } \\
\text { Shield }\end{array}$ & $\begin{array}{c}\text { C. } \\
\text { Inspect } \\
\text { Wind } \\
\text { Shield }\end{array}$ & $\begin{array}{l}\text { D. Use } \\
\text { Wind } \\
\text { Gauge }\end{array}$ & $\begin{array}{l}\text { E. Train Welders on } \\
\text { Proper Installation of } \\
\text { Wind Shields }\end{array}$ \\
\hline Ease of Implementation & 9 & 1 & 9 & 3 & 1 \\
\hline Cost Effectiveness & 3 & 3 & 3 & 3 & 3 \\
\hline Impact on Process & 1 & 9 & 9 & 3 & 9 \\
\hline Staff Efficiency & 3 & 3 & 3 & 3 & 3 \\
\hline Customer Satisfaction & 1 & 9 & 9 & 1 & 9 \\
\hline Total & 17 & 25 & 33 & 13 & 25 \\
\hline
\end{tabular}

Figure 6. Solutions to reduce wind impact. 
Figure 7 shows that to improve welder performance, developing standard welder training ( $F$ ) is the highest rated solutions.

\begin{tabular}{|c|c|c|c|c|c|}
\hline \multirow{2}{*}{$\begin{array}{l}\text { Desired } \\
\text { Characteristics }\end{array}$} & \multicolumn{5}{|c|}{ Solutions Options (Ways to improve welder performance) } \\
\hline & $\begin{array}{l}\text { F. Develop } \\
\text { Standard } \\
\text { Welder } \\
\text { Training }\end{array}$ & $\begin{array}{l}\text { G. Improve } \\
\text { Welder } \\
\text { Classification } \\
\text { Levels }\end{array}$ & $\begin{array}{l}\text { H. Implement } \\
\text { Annual Eye } \\
\text { Sight Test }\end{array}$ & $\begin{array}{l}\text { I. Improve } \\
\text { Welder } \\
\text { Allocations } \\
\text { to Projects }\end{array}$ & $\begin{array}{l}\text { J. Provide } \\
\text { Welders with } \\
\text { Weld Parameter } \\
\text { Check Sheet }\end{array}$ \\
\hline $\begin{array}{l}\text { Ease of } \\
\text { Implementation }\end{array}$ & 1 & 1 & 9 & 3 & 3 \\
\hline $\begin{array}{l}\text { Cost } \\
\text { Effectiveness }\end{array}$ & 9 & 3 & 3 & 9 & 9 \\
\hline $\begin{array}{l}\text { Impact on } \\
\text { Process }\end{array}$ & 9 & 3 & 3 & 3 & 3 \\
\hline $\begin{array}{l}\text { Staff } \\
\text { Efficiency }\end{array}$ & 3 & 9 & 9 & 9 & 1 \\
\hline $\begin{array}{l}\text { Customer } \\
\text { Satisfaction }\end{array}$ & 9 & 3 & 3 & 1 & 9 \\
\hline Total & 31 & 19 & 27 & 25 & 25 \\
\hline
\end{tabular}

Figure 7. Solutions to improve welder performance. 
Overall, although a robust body of literature exists with detailed information on these two methods individually, there is a gap in research and practice with respect to combining Lean and Six-Sigma into one framework for comprehensive improvement of modular construction processes.

\section{Sustainability and Energy Consumption}

Buildings consume a huge amount of energy and have an impact on climate changes, and air and water qualities in cities (Vyas et al. 2014). According to 2010 data, $45 \%$ of world energy and $50 \%$ of water were used by buildings (Dixon, 2010). When looked at environmental effects and problems, $23 \%$ of air pollution, $50 \%$ of greenhouse gas production, $40 \%$ of water pollution and $40 \%$ of solid waste in cities are associated with buildings. The author also mentioned that these environmental problems associated with the construction industry could be substantially decreased via changes in its operations and applications.

Sustainable building practices are growing and become an important trend in the building industry. Sustainable construction applies sustainable development principles to a building's life cycle, including deconstruction and management of wastes (Yilmaz \& Bakis, 2015). Construction and operating buildings consume more raw materials and energy than any other sector in the developed world (Keller, Clevenger \& Atadero, 2013). As such, the construction industry has identified the need for sustainable building practices.

\section{Energy Consumption Using System Dynamics Approach}

System Dynamics (SD) was a perspective and a set of conceptual tools that enabled us to understand the structure and dynamics of complex systems (Sterman, 2000). SD dealt with interaction of various elements of a system in time and captured the dynamic aspect by 
incorporating concepts such as stocks, flows, feedback and delays, and thereby provided an insight into the dynamic behavior of system over time (Tang \& Vijay, 2001). System Dynamics Model was used to analyze the resource requirements of New Orleans to construct different types of housing systems as it recovers from Hurricane Katrina (Quinn 2008). Regarding the measurement of energy consumption, Feng, Chen \& Zhang (2012) developed a SD model choosing Beijing as the case area of urban energy consumption. Their results showed that the total energy demand in Beijing was predicted to reach 114.30 million coals equivalent (Mtce) by 2030, while that value in 2005 was 55.99 Mtce, which would be 1.04 times higher than the level in 2005. SD model was also useful for approximating what the energy consumption was on a monthly or yearly basis (Quinn 2008). It brought benefits on other sectors as well. However, the application of Systems Dynamics on energy consumption of modular construction is very rare.

\section{Discrete Optimization in modular construction production}

Discrete Optimization was a branch of optimization in applied mathematics and computer science. Zawidzki and Nishikawa (2010) applied it in modular type of spatial truss system, such as truss-Z. Truss-Z was a structural and spatial truss system, which was originally designed for pedestrian traffic. Truss-Z had specific geometrical properties. For example, the truss network of truss- $Z$ connected a given number of terminals and allowed the creation of closed loops and the branching of paths. Zawidzki and Nishikawa (2010) used discrete optimization to minimize the total number of modules used, achieve the best alignment to the given paths, reduce network distance and maximize the network flow. Discrete optimization process through Firefly Algorithm (FA) was applied in scaffolding modular construction to optimize scaffolding schedule in order to generate scaffolding design, erection and dismantling scheme, their associated schedule, resource requirements and estimated cost (Liu, Hou \& Wang, 2014). 
Hamelin and Zmeureanu (2012) presented the optimization of single-family house using two objective functions, i.e. life cycle primary energy use (LCE) and cost (LLC). They created a dynamic simulation model using discrete optimization to simulate the annual heating and cooling energy consumption for the climate of Ste-Agathe-des-Monts, Quebec. As a result, they obtained an optimum insulation level which is greater than those values recommended by the energy efficient building regulation in Quebec. 


\section{CHAPTER III: RESEARCH DESIGN}

\section{Overview of Methodology}

This study used a quantitative research methodology. Fig. 8 shows the research progress of this study. It implemented Value Stream Mapping (VSM) as part of a Lean technique. This research used Six Sigma tools to identify the root causes of the problem. Figure 8 shows a deep analysis of problems in modular construction. Through Value Stream Mapping (VSM), the factors of the problems were quantified. Then Six Sigma tools were applied to identify the root cause of the problems. Those root causes identified were verified and confirmed through the implementation of loosely coupled multi-unit systems. After the confirmation of the root causes, the next step was to focus on possible areas of improvement. Those areas were quantified and verified through the application of a System Dynamics (SD) model. The Discrete Optimization process was applied to optimize the system. The findings demonstrated that the system worked and answered the research questions. 


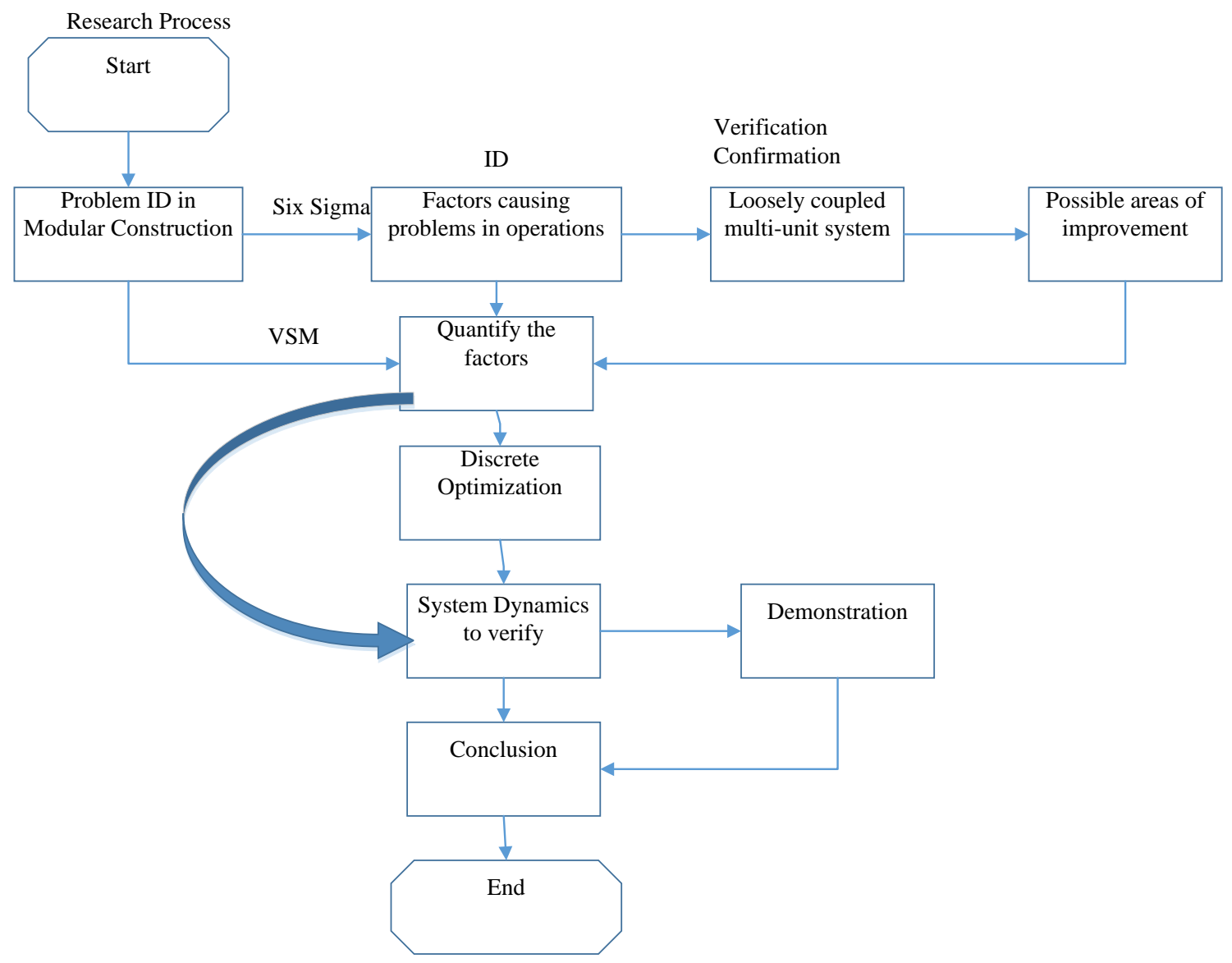

Figure 8. Research process of this study.

\section{Proposed Framework}

\section{Value Stream Mapping (VSM)}

This research applied VSM to document, analyze and improve the energy consumption of the production process of modular construction, including the flow of materials and resources required to produce a module. First, the author drew a current-state map to identify the factors responsible for inefficient use of energy. Then the author created a future-state map to find possible ways to reduce unnecessary consumption of energy. Fig. 9 shows the current-state map, 
which shows the selection of a value stream. Using the production flow of a door as an example, the figure supposes it goes through eight stages from the time when the weekly order of the door is received by the supplier to the time when the customer accepts the door. In this process, cycle time (CT), defects, takt time (Tk) and change over time (COT) are the possible factors identified at each station that are responsible for the inefficiency of energy consumption. The factors are marked as red in Fig. 9. Their consumptions of energy will be measured by multiplying the time spent times the power of the equipment used in the process.

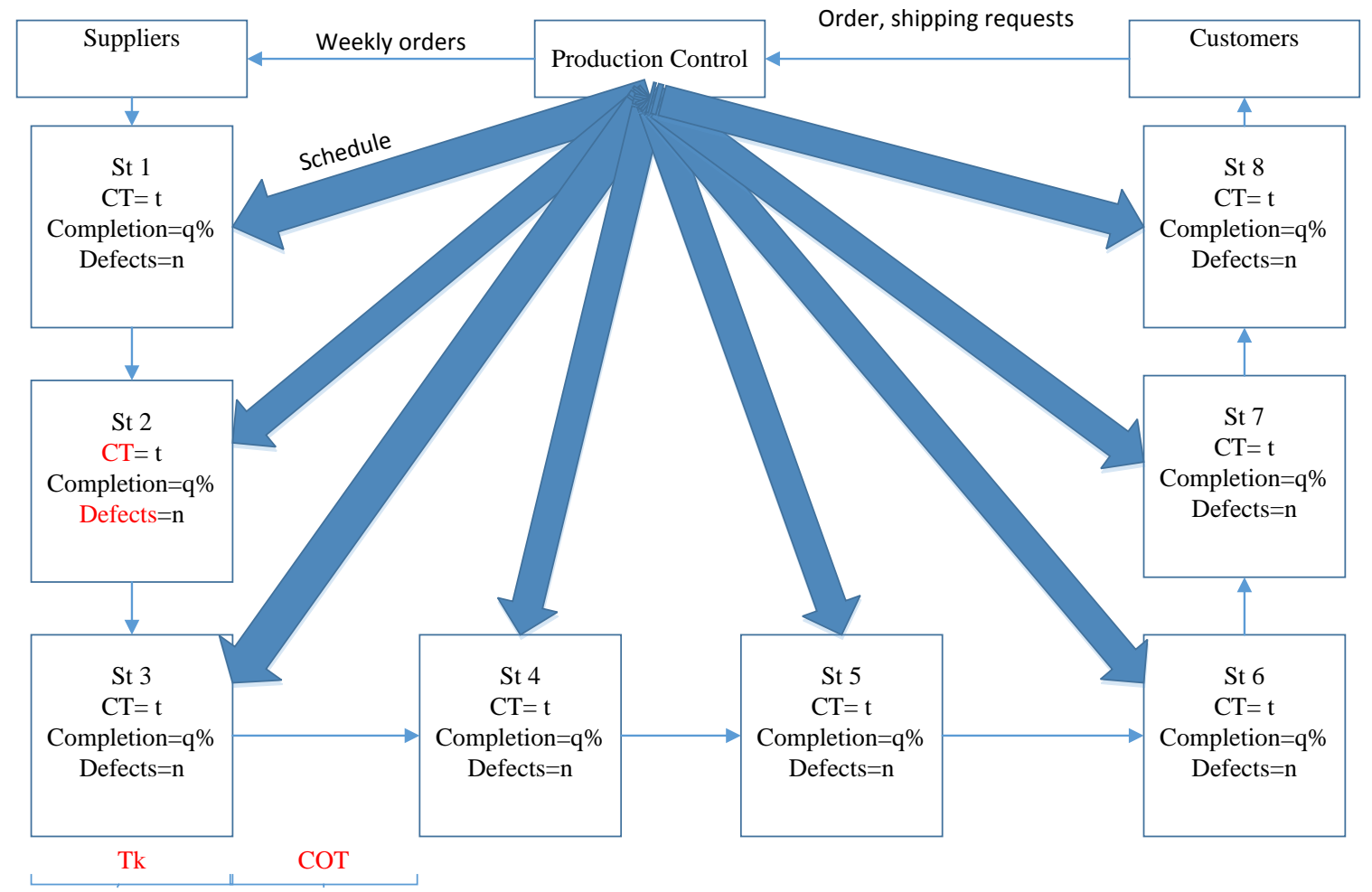

Figure 9. Current VSM to identify factors that waste energy. 


\section{System Dynamics (SD) For Verification}

In an SD model, Stocks represent materials, knowledge, people, money etc. Flows in an SD model represent the rates of changes, which show how stock values change and define the system's dynamics. In the Value Stream Mapping (VSM) model of Fig. 9, the Materials, Equipment, Cycle Time (CT), Takt Time (Tk), Defect Rate are considered as Stocks which represent the locations where the operations take place. The operations lead to a change in value. The flows in Fig. 9 include Change over Time (COT), Cycle Time (CT), which affect the values of the variables of Defects, Cycle Time (CT), Completion Rate, Takt Time (Tk). The variables lead to energy consumption.

Fig. 10 shows the System Dynamics (SD) palette, the author added two stocks called Material Equipment and Energy Consumption in the model. Then the author first added the flow of "Cycle Time (CT)" from the stock of Material Equipment to the stock of Energy Consumption (EC). In the next step, the author defined the parameters and dependencies as discussed above. After that, the author added two parameters called initial energy consumption (denoted as InitialEngCon in SD system) and duration of cycle time (denoted as CTduration in SD system) to the system and made them as dependencies of stocks and flows. In the fourth step, the author defined the formula for the flow of CT. In the fifth step, the author ran the model for approximately 15 seconds to show the change of energy consumption due to cycle time (CT) for every station. The time used in the fifth step is only for the demonstration of the SD system. The task durations used in analysis will be explained in the Data Collection section. The energy consumption (EC) value is the indicator for energy efficiency. When EC is greater than a certain threshold value, waste factors should be analyzed and improvement would be proposed. The calculation of the threshold value will be discussed in Chapter 4 . 


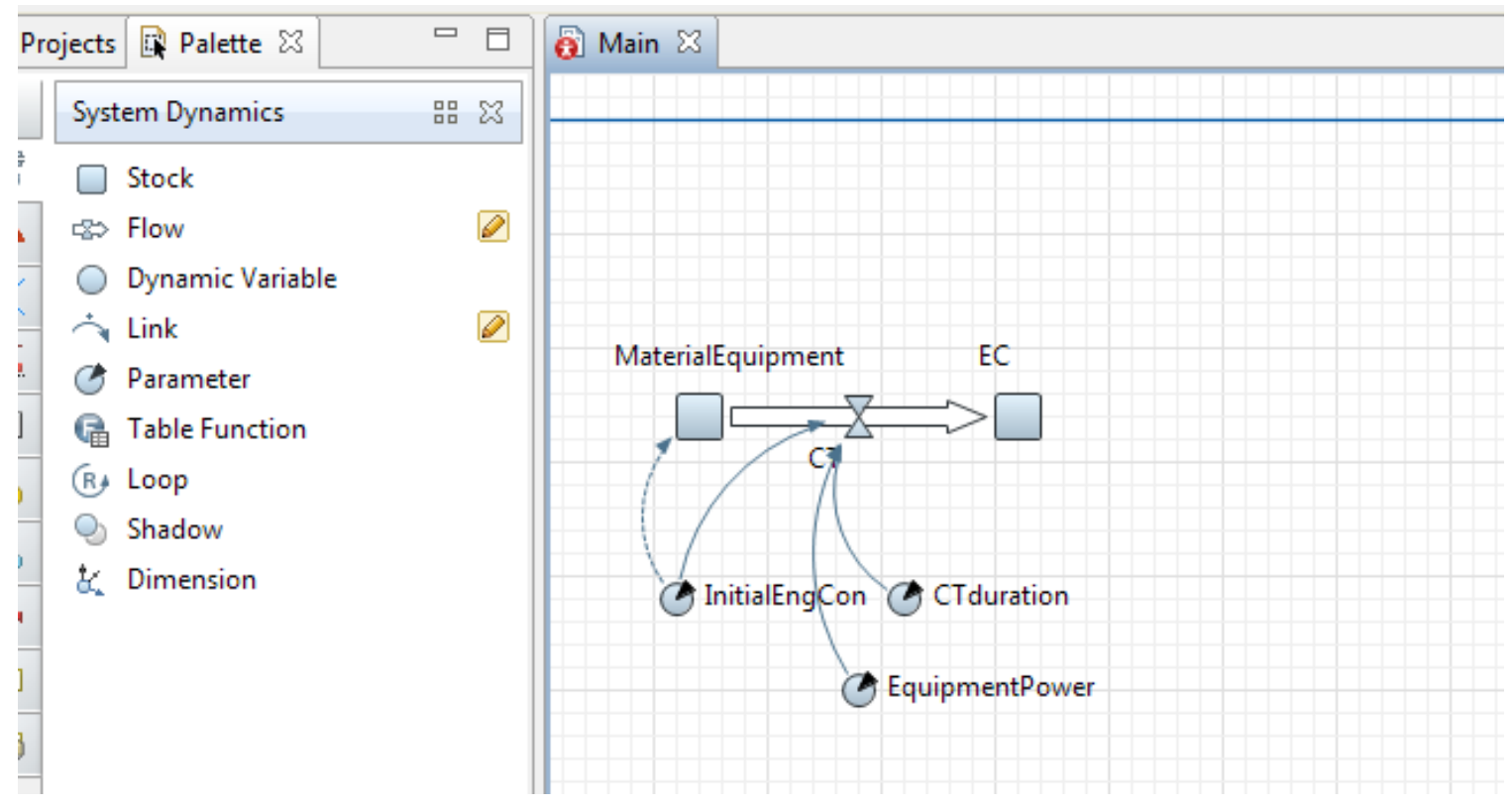

Figure 10. System dynamics model of energy consumption.

After identifying the waste factors, the author analyzed the manufacturing process of building modules to identify root cause(s) of factors responsible for energy consumption and implemented changes to improve the process following the part of a DMAIC (Define, Measure, Analysis, Improve, Control) approach. The author limited the research to Improve Phase as part of application of DMAIC approach since Control Phase was out of the scope of this research. In the Define Phase, the author clarified the purpose and scope to identify the root causes. In addition, the author gathered the information of the existing measurement system for quantities showing how much energy was consumed. An energy measurement system was applied in this phase. In the Analyze Phase, the author identified the potential causes of factors that waste energy. Fig. 11 lists the potential root causes in each category, including machines (i.e. equipment), methods (i.e. how work is done), people (i.e. human elements), environment (i.e. buildings, logistics, space), materials (i.e. raw materials), and measurement (i.e. calibration, standard). In the improvement 
phase, the solutions of the potential root causes were developed through Discrete Optimization process.

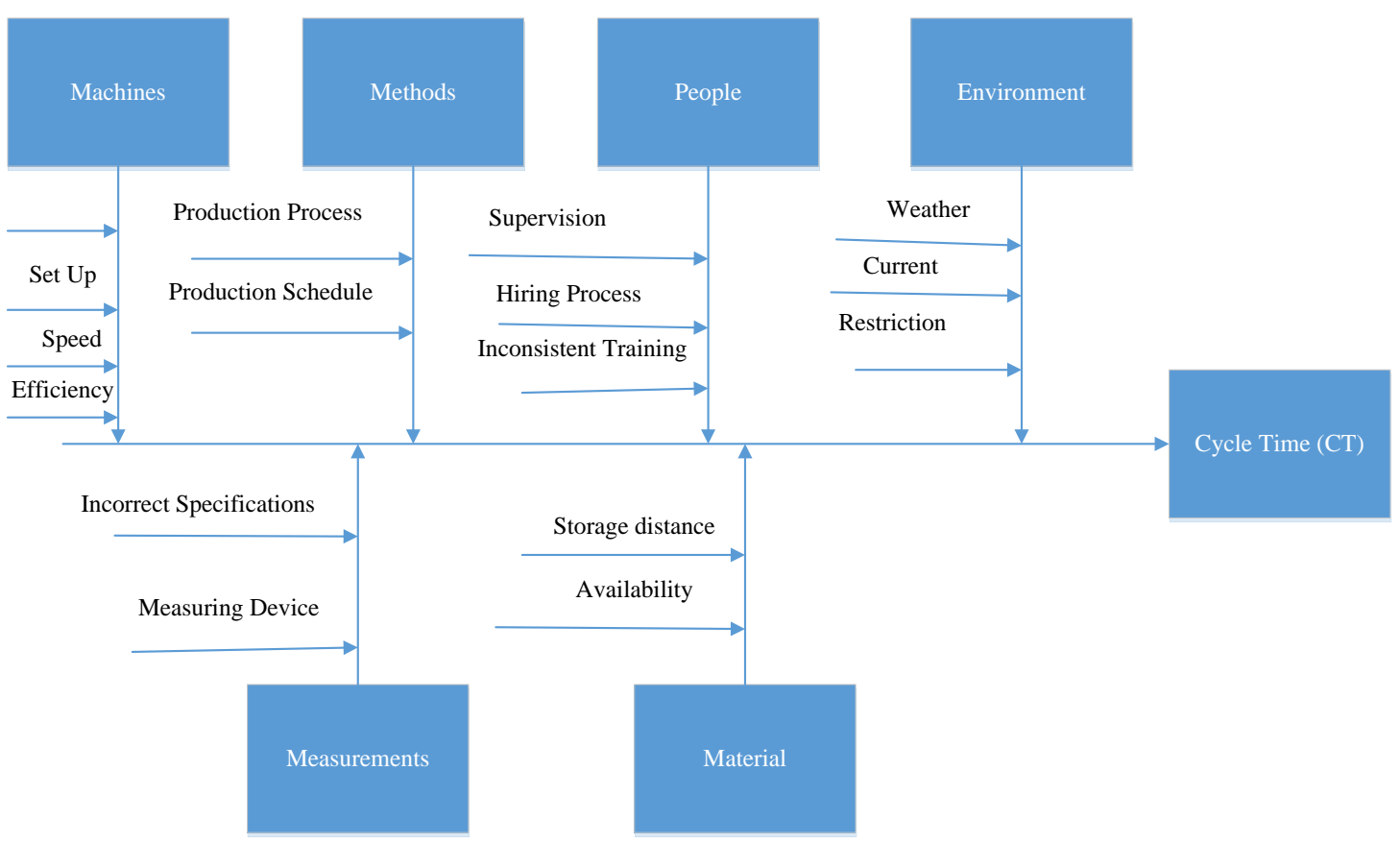

Figure 11. Potential causes of longer cycle time using six sigma methodology.

\section{Loosely Coupled Multi-Unit System}

In modular construction, modules are produced by following a step-by-step process in each station. Therefore, work of one station affects the work in subsequent stations. Thus, one activity of a station is loosely related (or tightly interdependent) with other activities. If two stations or tasks have few variables in common, compared to other variables influencing the activity, they are defined as loosely coupled sets. Loosely coupled system depends on its environment and complexity. In a loosely coupled system, any modifications or changes in an activity cannot affect the entire system. 
Fig. 12 below shows how modular construction is loosely coupled. There were 6 root causes in previous figure (Fig. 12). Among the 6 causes, assume that the Machines, Material and Environment are all involved with the process Methods and they have strong direct effects on the production process. On the other hand, the author assumed that the factor of People is not directly related to the factor of Methods, but it is directly related to the factors of Measurement and Machines. So, the factor of People has an indirect effect on the factor of Methods. For example, if the employees of a company are not trained well, they will not be able to use machines properly, which will eventually affect the production process of the company. Therefore, their effects are important to calculate the eigenvalue.

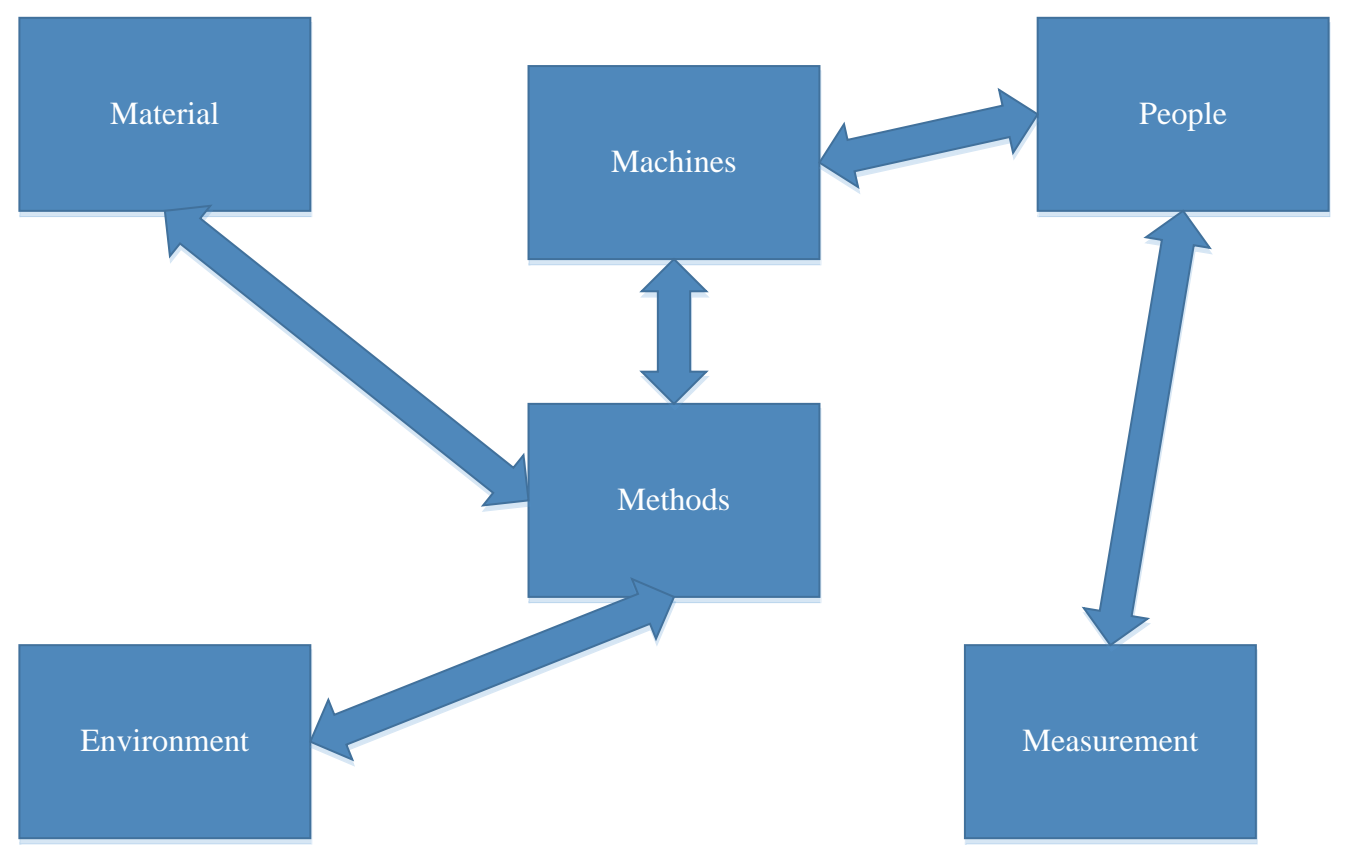

Figure 12. Modular construction as a loosely coupled system. 
The Power Method can be used to calculate the dominant eigenvector for the relationships shown in Fig. 12. Matrix K method is able to approximate the corresponding eigenvalues to identify the most important root cause. When using Power Method to calculate dominant eigenvectors, the author assumed that matrix A had the dominant eigenvalue with corresponding dominant eigenvectors. Then the author chose an initial approximation $\mathrm{X}_{0}$ of one of the dominant eigenvectors of $A$, where vector $\mathrm{X}_{0} \in \mathrm{R}^{\mathrm{n}} \neq 0$. The following equations show the calculation sequence. In this way, it is possible to obtain a good approximation of the dominant eigenvector A, which consequently leads to finding corresponding dominant eigenvalues (which is the largest in absolute value).

$\mathrm{X}_{1}=\mathrm{AX}_{0}$

$\mathrm{X}_{2}=\mathrm{AX} X_{1}=\mathrm{A}\left(\mathrm{AX}_{0}\right)=\mathrm{A}^{2} \mathrm{X}_{0}$

$\mathrm{X}_{3}=\mathrm{AX} \mathrm{X}_{2}=\mathrm{A}\left(\mathrm{A}^{2} \mathrm{X}_{0}\right)=\mathrm{A}^{3} \mathrm{X}_{0}$

$\mathrm{X}_{\mathrm{K}}=\mathrm{A} \mathrm{X}_{\mathrm{k}-1}=\mathrm{A}\left(\mathrm{A}^{\mathrm{k}-1} \cdot \mathrm{X}_{0}\right)=\mathrm{A}^{\mathrm{k}} \mathrm{X} 0$

Eigenvalues are a special set of scalars associated with a linear system of equation (i.e. a matrix equation) that are sometimes also known as characteristic roots, characteristic values (Hoffman and Kunze 1971), proper values, or latent roots (Marcus and Minc 1988, p. 144). A large eigenvalue indicates that with high chance the item (which carries the eigenvalue) would be the important root cause of the problem. The following steps show how to use Matrix K Method to find dominant eigenvalues.

Let $\mathrm{A}$ be a matrix, then if there is a vector $\mathrm{X}_{0} \in \mathrm{R}^{\mathrm{n}} \neq 0$ such that

$$
\mathrm{A} \mathrm{X}_{0}=\lambda \mathrm{X}_{0}
$$

For some scalar $\lambda$, then $\lambda$ is called the eigenvalue of A with corresponding eigenvector $\mathrm{X}_{0}$. 
Assume that $\mathrm{A}$ is a $\mathrm{K}$ by $\mathrm{K}$ matrix with eigenvalue $\lambda$. The following equation show the calculation of $\mathrm{A}$.

$$
\mathrm{A}=\left[\begin{array}{ccc}
a 11 & \cdots & a 1 k \\
\vdots & \ddots & \vdots \\
a k 1 & \cdots & a k k
\end{array}\right]
$$

Then the corresponding eigenvectors satisfy the following condition:

$\left[\begin{array}{ccc}a 11 & \cdots & a 1 k \\ \vdots & \ddots & \vdots \\ a k 1 & \cdots & a k k\end{array}\right]\left[\begin{array}{c}x 1 \\ . . \\ x k\end{array}\right]=\lambda\left[\begin{array}{c}x 1 \\ . \\ x k\end{array}\right]$

Which is equivalent to the following homogenous system:

$\left[\begin{array}{ccc}a 11-\lambda & \cdots & a 1 k \\ \vdots & \ddots & \vdots \\ a k 1 & \cdots & a k k-\lambda\end{array}\right]\left[\begin{array}{c}x 1 \\ . \\ x k\end{array}\right]=\left[\begin{array}{c}0 \\ . \\ 0\end{array}\right]$

This formula can be written as the following equation:
$(\mathrm{A}-\lambda \mathrm{I}) \mathrm{X}_{0}=0$
(Eq. 3)

Where I is the identity matrix. According to Cramer's rule, a linear system of equations has nontrivial solutions if and only if the determinant vanishes, so the solution of Eq. (3) is given by

$$
\operatorname{det}(\mathrm{A}-\lambda \mathrm{I})=0
$$

After solving the above equation, it is possible to find out the eigenvalue $\lambda$.

The system in this research considers each category as a square matrix and the areas under each category will be considered as components of the matrix.

For example, to verify if the "Machines" is most likely to be a root cause, Machines can be defined as matrix $A$. Then if there is a vector $X_{0} \in R^{n} \neq 0$ such that

$$
\mathrm{A} \mathrm{X}_{0}=\lambda \mathrm{X}_{0}
$$

For some scalar $\lambda$, then $\lambda$ is called the eigenvalue of $\mathrm{A}$ with corresponding eigenvector $\mathrm{X}_{0}$.

Each area of the Machines can be defined in the following equations:

Calibration $=\mathrm{a}_{11}$ 
Set $u p=a_{12}$

Speed $=\mathrm{a}_{12}$

Efficiency $=\mathrm{a}_{22}$

So, matrix $A$ is a $2 \times 2$ matrix. The following equation calculates the eigenvalue $\lambda$ of matrix A.

$\mathrm{A}=\left(\begin{array}{ll}a 11 & a 12 \\ a 21 & a 22\end{array}\right)$

The corresponding eigenvectors satisfy the following equation:

$\left(\begin{array}{ll}a 11 & a 12 \\ a 21 & a 22\end{array}\right)\left(\begin{array}{l}x 1 \\ x 2\end{array}\right)=\lambda\left(\begin{array}{l}x 1 \\ x 2\end{array}\right)$

The above equation is equivalent to the homogenous system as calculated in (Eq. 4) below.

$\left(\begin{array}{cc}a 11-\lambda & a 12 \\ a 21 & a 22-\lambda\end{array}\right)\left(\begin{array}{l}x 1 \\ x 2\end{array}\right)=\left(\begin{array}{l}0 \\ 0\end{array}\right)$

Eq. (4) can be written as Eq. (5)

$$
(\mathrm{A}-\lambda \mathrm{I}) \mathrm{X}_{0}=0
$$

Where I is the identity matrix. According to Cramer's rule, a linear system of equations has nontrivial solutions if and only if the determinant vanishes, so the solution of equation (5) is given by the following equation:

$$
\operatorname{det}(\mathrm{A}-\lambda \mathrm{I})=0
$$

Eq. (6) is called a "characteristic equation" of A. The solutions of this equation are

$$
\lambda^{2}-\lambda\left(\mathrm{a}_{11}+\mathrm{a}_{22}\right)+\left(\mathrm{a}_{11} \mathrm{a}_{22}-\mathrm{a}_{12} \mathrm{a}_{21}\right)=0 \quad \text { (Eq. 7) }
$$

Eq. (7) calculates the eigenvalue of matrix A. It is also applicable to measure the eigenvalues of any category. The largest eigenvalue will be taken as a possible area of improvement.

In order to demonstrate the eigenvalue model, the author designed a dormitory module room of 10 feet long, 8 feet wide and 8 feet tall in size using Revit software (See Fig. 13 and Fig. 14 for details). Each module includes a door and two windows. It uses wood for floor and wall frames. 


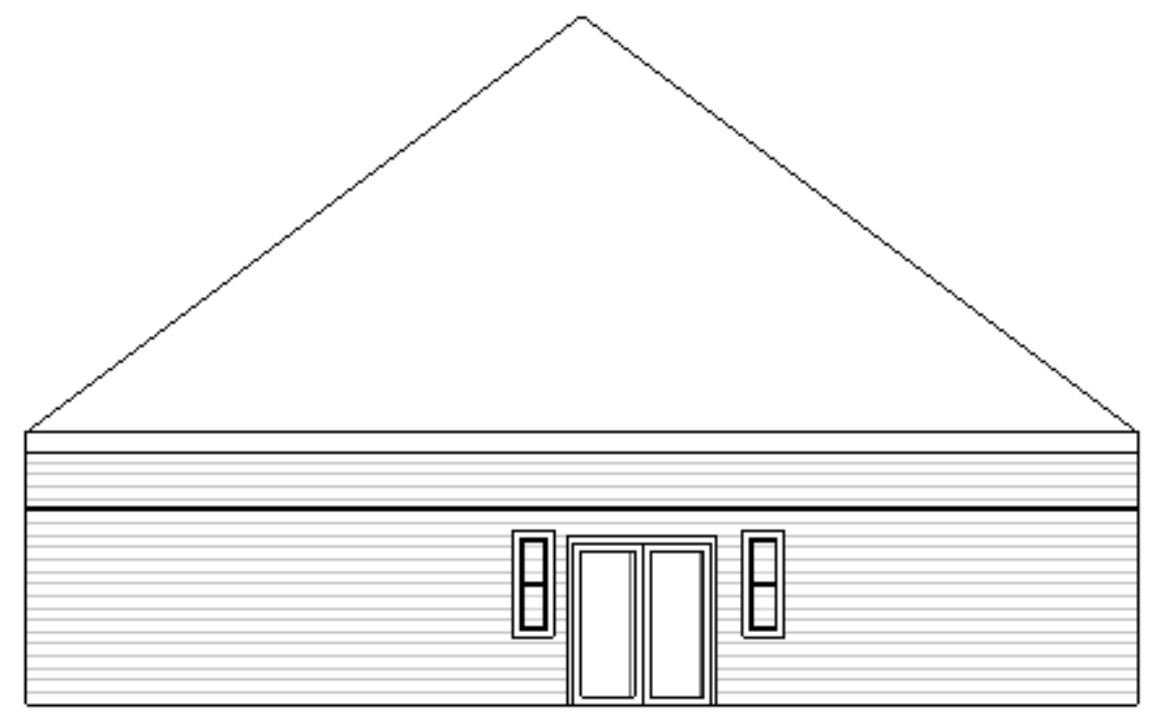

Figure 13. Dormitory project.

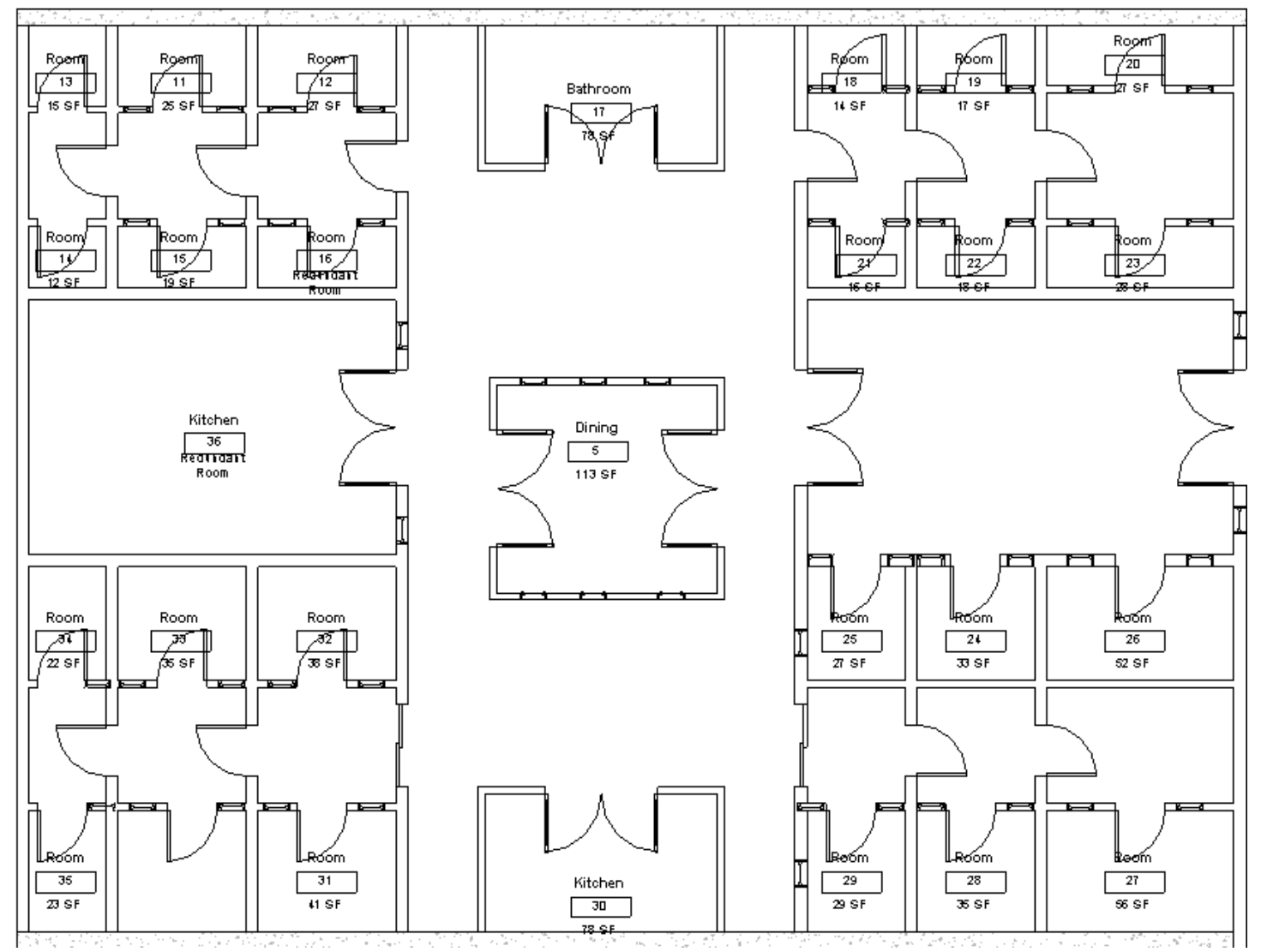

Figure 14. Floor plan view of a dormitory project and module room. 


\section{Discrete Optimization}

The following calculation uses Little's Law in queuing theory to find out the average number of customers in a queuing system:

$$
l=\lambda_{w}
$$

where,

$1=$ The average number of customers in a queuing system

$\chi=$ The rate at which the customers arrive and enter the system $\mathrm{w}=$ Average sojourn time of a customer

The second step of discrete optimization in this research is to apply Little's Law in a VSM system. The VSM system consists of several stations to produce modules for prefabricated buildings. Eq. (8) below shows the calculation of work-in-process:

$$
\mathrm{WIP}=\mathrm{TH} * \mathrm{CT} \quad(\text { Eq. } 8)
$$

where,

WIP (Work-In-Process) $=$ The parts of the modules not yet completed in the factory

$\mathrm{TH}($ Throughput $)=$ The average quantity of modules (non-defective) produced per unit time.

CT $($ Cycle Time $)=$ The elapsed time from modules creation start to modules completion .

It includes processing time, transportation time, queue time, hold time etc.

From above equation, Eq. (9) calculates cycle time:

$$
\mathrm{CT}=\mathrm{WIP} / \mathrm{TH}
$$

Therefore, CT can be reduced (or improved) by reducing WIP and/or increasing TH. 
The third step is to reduce CT and increase TH. The definition of Critical WIP (W0) indicates the WIP level in which a production line without congestion would achieve maximum throughput (i.e. Rb) with minimum cycle time (i.e. T0). The following equation calculates critical work-in-process,

$$
\mathrm{W}_{0}=\mathrm{Rb}^{*} \mathrm{~T}_{0}
$$

where,

$$
\mathrm{W}_{0}=\text { Critical WIP }
$$

$\mathrm{Rb}($ Bottleneck Rate $)=$ The rate of the process center having least long-term capacity with highest long-term utilization.

$\mathrm{T}_{0}=$ Raw Processing time $=$ Sum of long-term average processing time at each work-station in a line The calculations of CT and TH for different W (WIP values) are shown below. The equations below show that increasing Rb can improve both TH and CT when WIP levels are above W0.

$$
\begin{aligned}
& \mathrm{CT}=\mathrm{T} 0 \text { if } \mathrm{W}<=\mathrm{W} 0 \\
& \mathrm{~W} / \mathrm{Rb} \text { if } \mathrm{W}>\mathrm{W} 0 \\
& \mathrm{TH}=\mathrm{W} / \mathrm{T} 0 \text { if } \mathrm{W}<=\mathrm{W} 0 \\
& \mathrm{Rb} \text { if } \mathrm{W}>\mathrm{W} 0
\end{aligned}
$$

The fourth step is to increase $\mathrm{Rb}$ (Bottleneck Rate). In this research, the author assumed that processing rate of different stations are $X_{1}, X_{2}, X_{3}, X_{4}$ (shown in fig. 15), where,

$$
\begin{aligned}
& X_{1}<X_{2}, \\
& X_{2}=X_{3}, \\
& X_{3}>X_{4} .
\end{aligned}
$$


So, the bottle neck is $\mathrm{X}_{4}$ since this is the least processing rate among all other stations. The author then divided the whole system of module production into 4 stations, which were operated based on the production schedule.

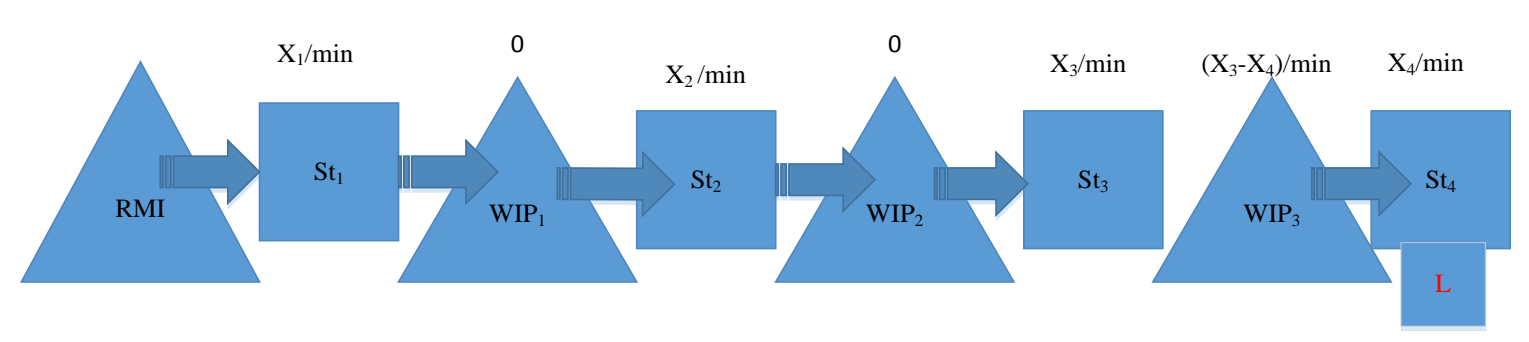

Figure 15. Discrete optimization based on Little's Law.

Fig. 15 shows that RMI is releasing the material into the process at the rate of the first operation. St1 processes $\mathrm{X}_{1}$ parts per minute and places it in WIP1, where it waits for St2. Meanwhile, St2 processes $X_{2}$ parts (which is greater than $X_{1}$ ) per minute. Since St2 processes more parts than St1 on average, no parts accumulate in WIP1.St2 feeds parts to St3 at the rate of $X_{2}$ per minute and St 3 processes them at the same rate (since $X_{2}=X_{3}$ ). Therefore, no work accumulates in WIP2 as well, given that there is no variability in cycle time. The output of St3 waits in WIP3 to be processed by St4. Because St4 can process less parts than St3, $\mathrm{X}_{3}-\mathrm{X}_{4}$ parts accumulate in WIP3, which leads to increase in cycle time (CT).

In order to increase the $\mathrm{Rb}$ and to make sure that no parts wait at WIP3 to be processed by the next station, the author assigned more people (L) to St4, possibly from another station during unutilized time. If the modules are to make with different dimensions and configuration, the production team will carefully analysis the demand and then prepare the production schedule. 
Then the schedule of each station will be distributed. The author placed the Quality Check (QC) in every station before bottleneck operation to reduce the number of defects. In order to reduce the change over time (COT) in case of equipment breakdown, replacement parts and repair personnel (RP) must be ready and close to the $\mathrm{St} 4$ as much as possible. The same procedure will be applicable for other stations with similar problems.

\section{Data Collection}

\section{RSMeans Building Construction Cost Data}

Data that aligned with the modular construction tasks were selected from RSMeans Building Construction Cost Data (2016). Generally, the following procedure was utilized to assemble task appropriate data:

1. Selection of task: To select tasks for analysis purpose.

2. Crew information: To gather the information about the number of workers that were needed to complete per unit for every task.

3. Labor Hours: It is the amount of labor required to perform one unit of work. This step is to record labor hours for selected tasks.

The examples of the tasks, crew information and labor hours are in the table below. 
Table 4

Tasks, Crew and Labor Information of One Sample

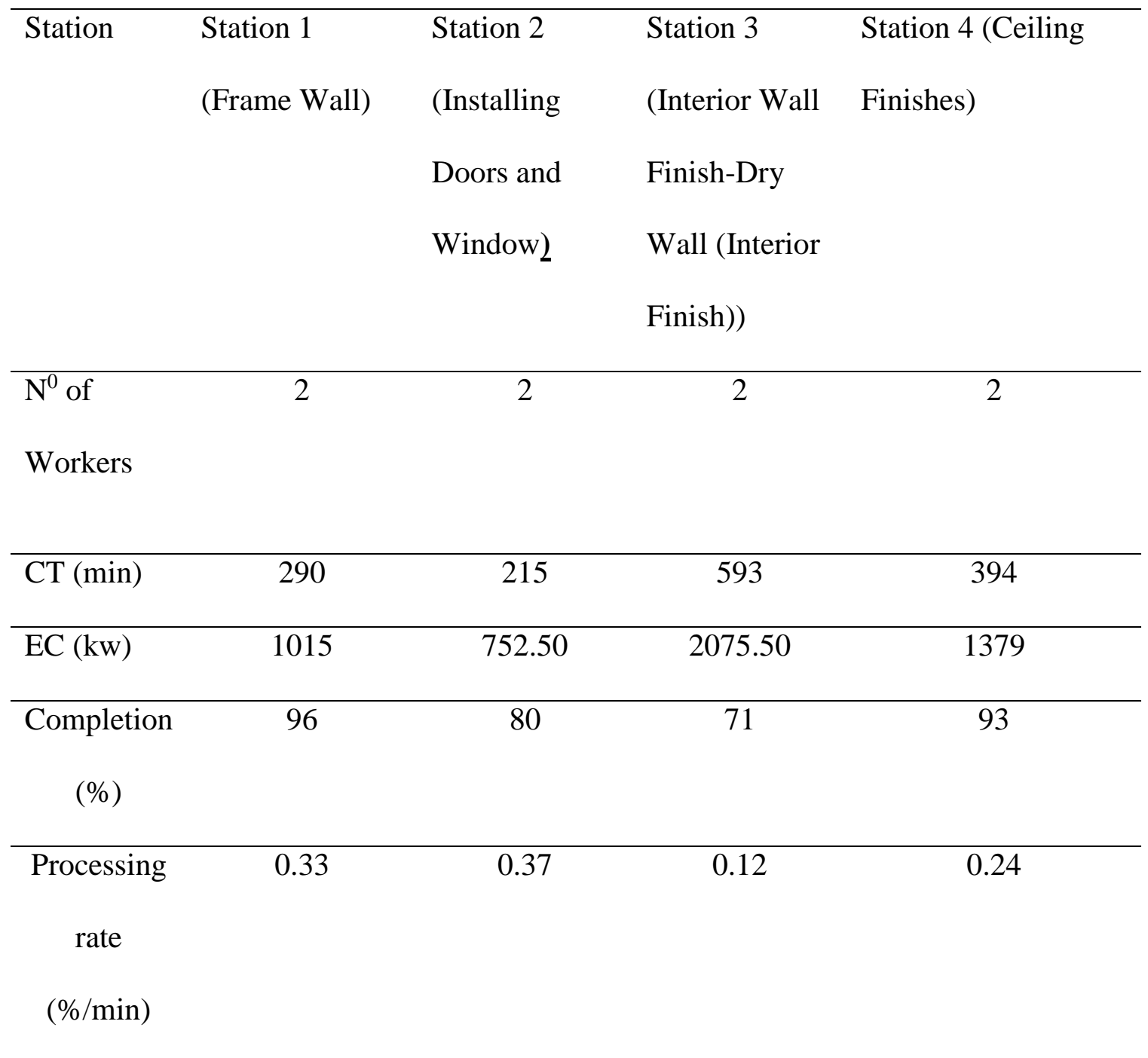

\section{Definitions}

Based on the information collected from RSMeans Cost Data Book and the room module, the author designed the following items used in the measurement of energy consumption:

Number of workers:

Worker per unit $\times$ Number of units needed 
Cycle time:

Labor hours per unit $\times$ Number of units needed

Completion rate (\%): The author made the assumption regarding the completion rate of the task of each station that no station completes less than $70 \%$ of total tasks within the scheduled cycle time and therefore, obtained some random numbers using the Random function of MS Excel software.

Processing rate $(\% / \mathrm{min})$ :

$$
\frac{\text { Completion rate }}{\text { Cycle time }}
$$

\section{Measurement of Energy Consumption (EC)}

Equipment Energy Consumption (kw/h): Collected from online source.

(Data Source: QHWPM, 2012)

Measurement of energy consumption: Equipment energy consumption*cycle time

\section{Calculation of Cycle Time (CT) Per Worker}

Amount of time one station has to spend on other stations to complete its unfinished work:

$$
\frac{100-\% \text { of completion }}{\text { Processing rate }}
$$

Actual Time for other station to complete its work:

$$
\text { It' s own CT - time spent by other stations on it' s station }
$$

Actual Processing rate of a station:

$$
\frac{\% \text { of completion }}{\text { Actual time to complete its work }}
$$

Actual time needed for a station to complete its remaining unfinished work:

$$
\frac{100-\% \text { of completion }}{\text { Actual processing time }}
$$


CT/Worker: Actual time needed for a station to complete its remaining unfinished

$\frac{\text { Work }}{\text { Number of workers assigned to that station }}$

\section{Reduced Energy Consumption (EC) After Adding Workers}

Reduced Cycle Time (CT) after adding workers:

Actual cycle time $-($ CT per worker $\times$ Number of workers added $)$

Reduced Energy Consumption (EC) after adding workers:

\section{Reduced Cycle Time×Equipment Energy Consumption}

After collecting data, the author will move on to analyze them in the next chapter using the appropriate methods to reveal the relationships, patterns, and trends among the data corresponding to task details required to build a room module. 


\section{CHAPTER IV: DATA ANALYSIS}

In this chapter, the collected data are analyzed and results of the data analysis are presented.

\section{Statistical Analyses}

Using the data analysis tool of MS Excel, the author ran paired two sample t-tests based on 55 observations to show the comparison of Energy Consumptions (ECs) before and after the application of Lean Six Sigma in the same system. Null hypothesis assumed that there would not be any difference in the means of the two groups of observations. Table 5 shows the results of the t-tests.

Table 5

Results of t-Test

\begin{tabular}{llc}
\hline & Before & After \\
\hline Mean & 1310,781818 & 1177,810545 \\
\hline Variance & 254686,97 & 55 \\
\hline Observations & 55 & \\
\hline Pearson Correlation & 0,724722238 & \\
\hline Hypothesized Mean Difference & 0 & \\
\hline df & 54 & \\
\hline t Stat & 2,620940195 & \\
\hline P(T<=t) one-tail & 0,005682756 & \\
\hline t Critical one-tail & 1,673564906 & \\
\hline P(T<=t) two-tail & 0,011365511 \\
\hline t Critical two-tail & 2,004879288 \\
\hline
\end{tabular}


One tail t-test is usually used when there is a direction in the hypothesis, for example, the mean value is below or above a certain number. This is the case in this study since the hypothesis in this research is that application of Lean Six Sigma reduces the energy consumption in modular construction. The author decided to use the $\mathrm{p}$ value and $\mathrm{t}$ critical one tail value. The sample group had 54 degrees of freedom because it contained 55 observations. As shown in Table 5, the Pearson Correlation is 0.724 , which is high. It means that the two variables are highly correlated. In Table 5, the value of a $\mathrm{t}$ Stat is 2.62 , which is higher than the value of t Critical of one-tail (which is 1.67). This means that there is a significant difference between the two samples. Because the calculated $\mathrm{p}$ value of the one-tail test is less than the alpha level of 0.05 , it means that with $95 \%$ confidence the data sample provides enough evidence to reject the null hypothesis for entire population.

\section{Other Types of Analyses}

\section{Analysis Using Loosely Coupled Multi-Unit System}

Table 6 shows a list of the major tasks of manufacturing module rooms. The data were collected from the RSMeans Building Construction Cost Data Book (2016, $74^{\text {th }}$ annual edition). Under the first task of Framing Walls at station 1, there were 4 different activities. The total hours of this task were broken down into labor hours needed by individual activity. 
Table 6

Schedule of a Room Module

\begin{tabular}{|c|c|c|c|c|}
\hline Description of the tasks & Quantity & Unit & $\begin{array}{l}\text { Labor } \\
\text { hours/u } \\
\text { nit }\end{array}$ & Total labors (min) \\
\hline St 1: Frame Wall & 36 & L. F & 0,133 & 290 \\
\hline Material Staging & 20 & & & \\
\hline Layout Wall Frame Plates & 20 & & & \\
\hline $\begin{array}{l}\text { Assemble wall frames on } \\
\text { working surface }\end{array}$ & 220 & & & \\
\hline $\begin{array}{l}\text { Assemble wall frame sections } \\
\text { into a room module }\end{array}$ & 30 & & & \\
\hline St 2: Installing Doors and Windows & & & & 215 \\
\hline Apply water resistant barrier & 80 & S. F & 0,002 & 10 \\
\hline Install window and door flashing & 40 & L. F & 0,008 & 20 \\
\hline Install door & 1 & E A & 1,23 & 75 \\
\hline Install windows & 2 & E A & 0,9 & 110 \\
\hline $\begin{array}{l}\text { St 3: Interior Wall Finish-Dry Wall } \\
\text { (Interior finish) }\end{array}$ & & & & 593 \\
\hline Install wiring for stitches and outlets & 4 & E A & 0,468 & 112 \\
\hline Install insulation & 288 & S. F & 0,006 & 100 \\
\hline $\begin{array}{l}\text { Install and finish } 5 / 8 \text { " fire-rated dry } \\
\text { wall }\end{array}$ & 288 & S. F & 0,017 & 295 \\
\hline Prime and paint dry wall & 288 & S. F & 0,005 & 86 \\
\hline St 4: Ceiling finishes & & & & 394 \\
\hline Install wiring for ceiling lights & 3 & E A & 0,468 & 84 \\
\hline Install insulation & 80 & S. F & 0,017 & 81 \\
\hline $\begin{array}{l}\text { Install and finish } 5 / 8 \text { " fire-rated dry } \\
\text { wall }\end{array}$ & 80 & S. F & 0,021 & 100 \\
\hline $\begin{array}{l}\text { Install spray applied acoustical } \\
\text { ceiling treatment }\end{array}$ & 80 & S. F & 0,027 & 129 \\
\hline
\end{tabular}

From the data in Table 6, the eigenvalue of the activity Frame Wall can be calculated. The following calculation defines Frame Wall activity as matrix B.

$\mathrm{B}=\left(\begin{array}{cc}20 & 20 \\ 220 & 30\end{array}\right)$ 
According to the characteristic equation of a $2 \times 2$ matrix, we found the following equation:

$$
\begin{aligned}
& \lambda^{2}-\lambda(20+30)+(20 * 30-220 * 20)=0 \\
= & \lambda^{2-}-50 \lambda-3800=0 \\
= & \lambda 1=91.5, \lambda 2=-41.5
\end{aligned}
$$

Since $\lambda 1>\lambda 2, \lambda 1=91.5$ is the dominant eigenvalue.

The following matrix $\mathrm{C}$ defines activity of Installing Doors and Windows.

$\mathrm{C}=\left(\begin{array}{cc}10 & 20 \\ 75 & 110\end{array}\right)$

According to the characteristic equation for a $2 \times 2$ matrix, the following equations calculate $\lambda$ :

$$
\begin{aligned}
& \lambda^{2}-\lambda(10+110)+(10 * 110-20 * 75)=0 \\
= & \lambda 2-120 \lambda-400=0 \\
= & \lambda 1=123.25, \lambda 2=-3.25
\end{aligned}
$$

Since $\lambda 1>\lambda 2, \lambda 1=123.25$ is the dominant eigenvalue.

The following matrix D defines activity of Interior Wall Finish-Dry Wall (Interior Finish)

$\mathrm{D}=\left(\begin{array}{cc}112 & 100 \\ 295 & 86\end{array}\right)$

According to the characteristic equation for a $2 \times 2$ matrix, the following equations calculate $\lambda$ :

$$
\begin{aligned}
& \lambda^{2}-\lambda(112+86)+(112 * 86-100 * 295)=0 \\
= & >{ }^{2}-198 \lambda-19868=0 \\
= & \lambda_{1}=271.25, \lambda_{2}=-73.25
\end{aligned}
$$

Since $\lambda_{1}>\lambda_{2}, \lambda_{1}=271.25$ is the dominant eigenvalue.

The following matrix E defines activity of Ceiling Finishes

$\mathrm{E}=\left(\begin{array}{cc}84 & 81 \\ 100 & 129\end{array}\right)$

According to the characteristic equation for a $2 \times 2$ matrix, the following equations calculate $\lambda$ : 


$$
\begin{aligned}
& \lambda^{2}-\lambda(84+129)+(84 * 129-81 * 100)=0 \\
\Rightarrow & \lambda^{2}-213 \lambda+2736=0 \\
\Rightarrow & \lambda_{1}=199.27, \lambda_{2}=13.73
\end{aligned}
$$

Since $\lambda_{1}>\lambda_{2}, \lambda_{1}=199.27$ is the dominant eigenvalue.

From the above results, it is obvious that the eigenvalue of Activity D (Install Wall Finish-Dry Wall (Interior Finish)) is the highest, which indicates that Activity D is most likely responsible for the root cause of longer cycle time which needs to be improved.

\section{Analysis Using System Dynamics}

A 10 feet by 8 feet room with a door and two windows, four outlets and 2 switches.

Machines used: Wood PVC door panel making machine

Energy Consumption (per hour): $210 \mathrm{kw}=3.5 \mathrm{kw}$ per minute

(Data Source: QHWPM, 2012)

Figs. 16, 17, 18, and 19 show the screen shot of the simulation using System Dynamics software to see change in Energy Consumption (EC) of station 1. They show the change of energy consumption from the initial phase (MaterialEquipment) to later phase (EnergyConsumption) due to change of $\mathrm{CT}$. The values of all the stations demonstrate the effect of CT on energy consumption and prove the functionality of the model. The flows that will cause more energy consumption are the main factors causing the inefficiency problem in energy consumption. In Fig 16, 17, 18, 19 below, they show the EC of station 1, station 2, station 3 and station 4 respectively after running the simulation for CT of 290, 215, 593 and 394 minutes respectively. The minus value in the model indicates that energy, material or efficiency of equipment are being consumed when the value of CT keeps changing. 


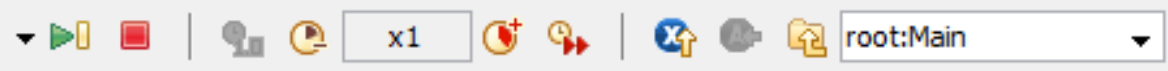

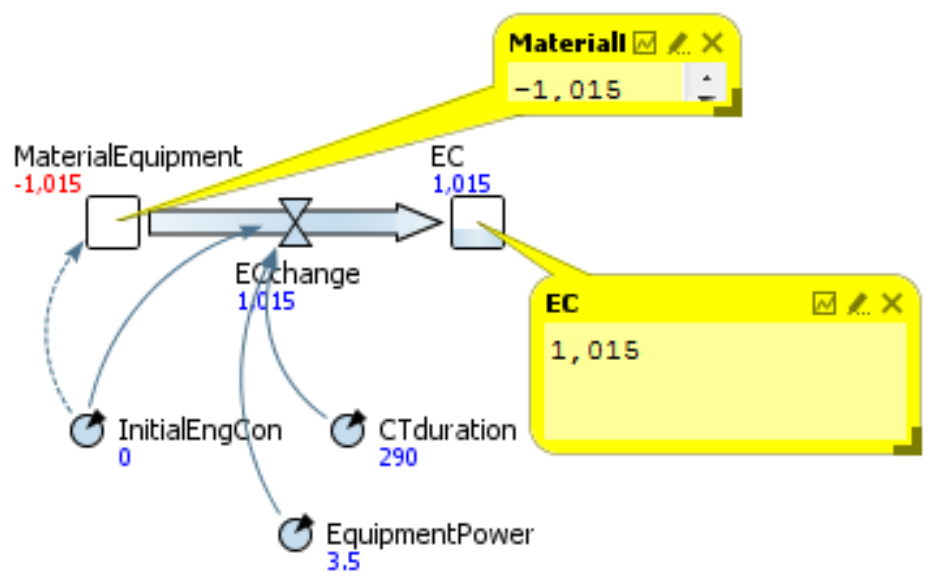

Figure 16. Energy consumptions of station \#1.

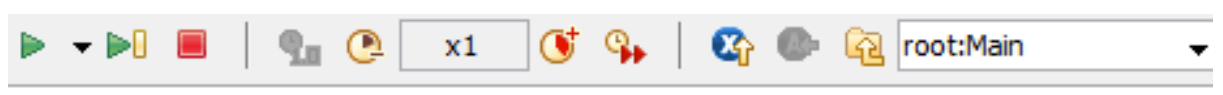

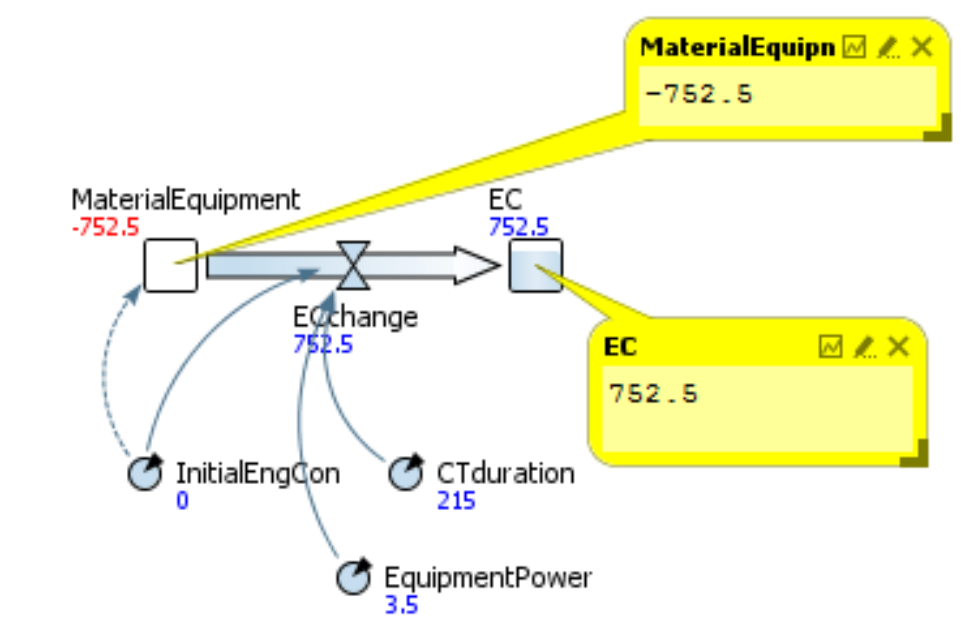

Figure 17. Energy consumptions of station \#2. 


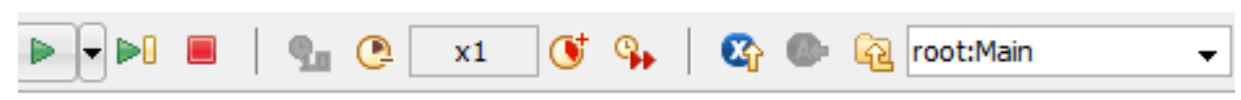

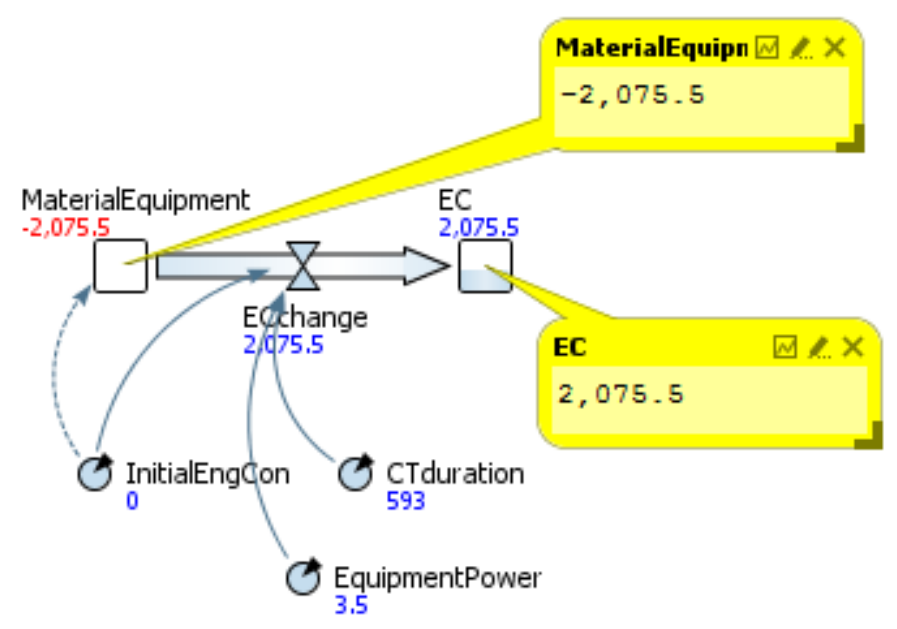

Figure 18. Energy consumptions of station \#3.

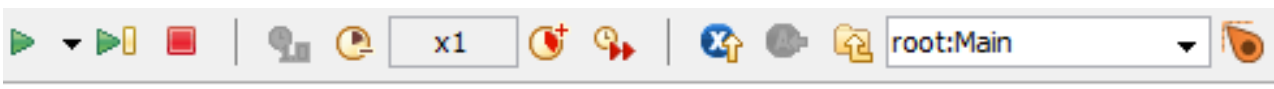

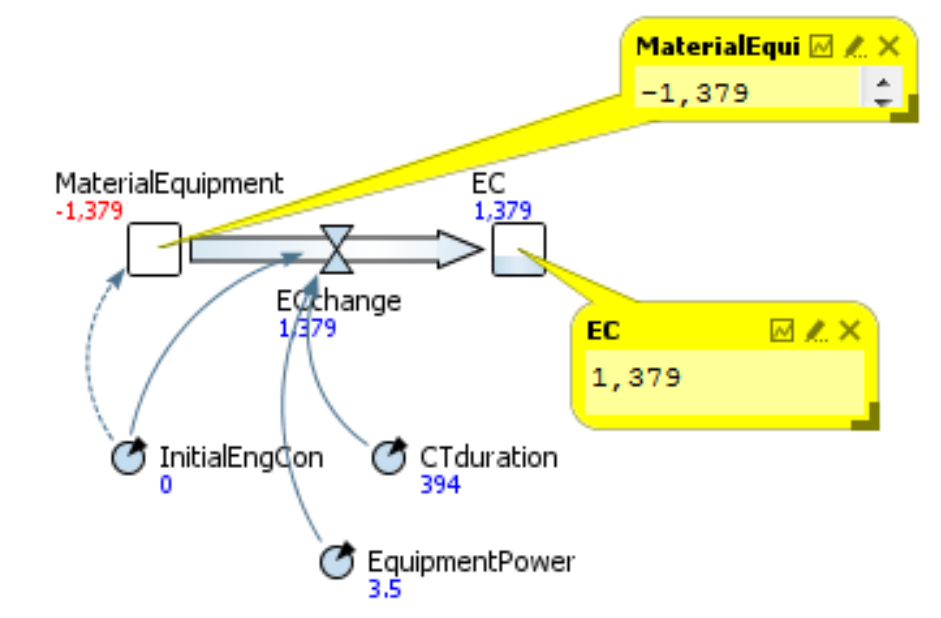

Figure 19. Energy consumptions of station \#4. 
On the figures above, the assumption is that the value of initial energy consumption (InitialEngCon) was zero.

\section{Analysis Using Discrete Optimization}

Machines used: Wood PVC door panel making machine

Energy Consumption (per hour): $210 \mathrm{kw}=3.5 \mathrm{kw}$ per minute)

The data collected from all tasks in Table 6 , show a significant time variance between the stations, indicating the importance to balance the total time in each station. Consequently, there exist significant variations in terms of energy consumed by each station in Fig. 20. Fig. 20 shows that EC is higher in St 3, where cycle time is the highest among all the stations, which is 593 $\min$.

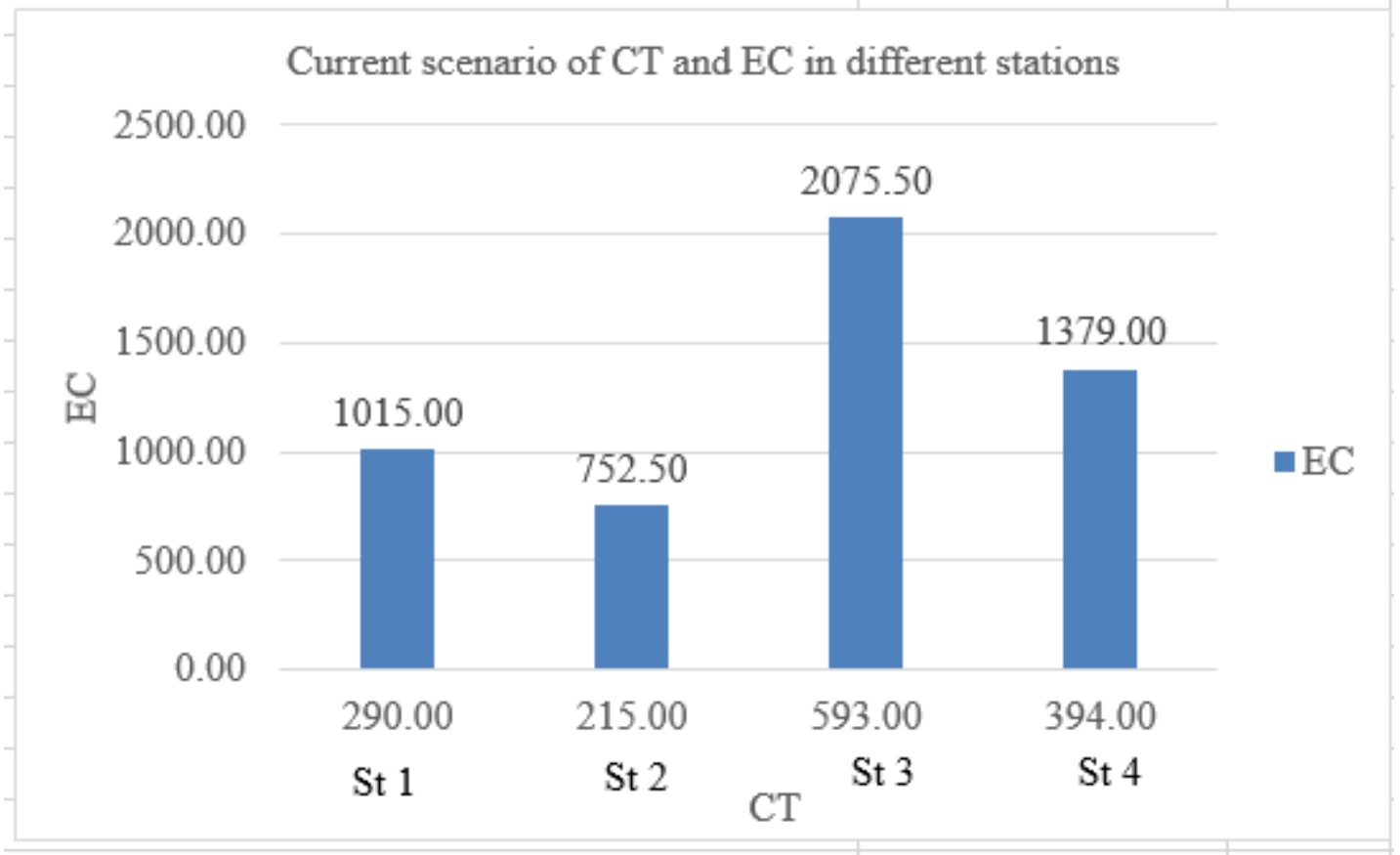

Figure 20. Current situation of cycle time and energy consumption. 
Therefore, the optimization process should focus on reducing the cycle time of station 3 by managing the related labor units and moving them from different stations to station 3 when they are needed.

\section{Bottleneck rate of St 3 and when Processing rate of St $3\left(X_{3}\right)<$ Processing rate of St $2\left(X_{2}\right)$}

From the data mentioned in Table 4, we noticed that processing rate of St $3(0.12 \% / \mathrm{min})$ was less than any other stations. Therefore, it was considered as bottleneck.

Under the above situation, St 3 was the bottleneck since it had the lowest processing rate and also the highest energy consumption $(2075.50 \mathrm{kw})$. From the data mentioned in Table 4, the completion rate of tasks at St 2 was $80 \%$ within the scheduled cycle time. Without changing the scheduled cycle time, that means the $20 \%(100 \%-80 \%)$ unfinished tasks could be completed in St 3, while the workers were waiting between St 2 and St 3 to move to stations 3. But since some tasks were already in process in St 3 and St 3 was processing the task at a rate lower than St 2, workers at St 2 had to wait for the workers at St3 to complete their unfinished work until workers at St 3 were ready to accept the task from St 2. Therefore, the amount of time that workers at St 2 spent on waiting for St 3 is calculated as follows:

$(100-80) / 0.37=53.75 \mathrm{~min}$, where 0.37 is the processing rate of St 2.

If $\mathrm{St} 3$ can synchronize with $\mathrm{St} 2$, the time left for $\mathrm{St} 3=593-53.75=539.25 \mathrm{~min}$. So, the actual processing rate of St 3 is calculated as follows:

$$
\operatorname{Pr} 3=71 \% / 539.25=0.13 \% / \mathrm{min}
$$

From Table 4, the remaining work of St 3 is $(100-71)=29 \%$. Therefore, the amount of time that St 3 had to spend to complete its remaining work is calculated as follows:

$29 \% / 0.13 \% / \mathrm{min}=220.26 \mathrm{~min}$ 
Since a total of 2 workers are involved in St 3, the cycle time per worker (CT/per worker) is calculated as follows:

$220.26 \mathrm{~min} / 2$ workers $=110.13 \mathrm{~min} /$ worker

From the above calculation, for every additional worker in St 3, CT could be reduced by 110.13 min. Figs. 21, 22 and 23 show how EC in St 3 is reduced when cycle time is reduced after adding additional units of labor from other stations.

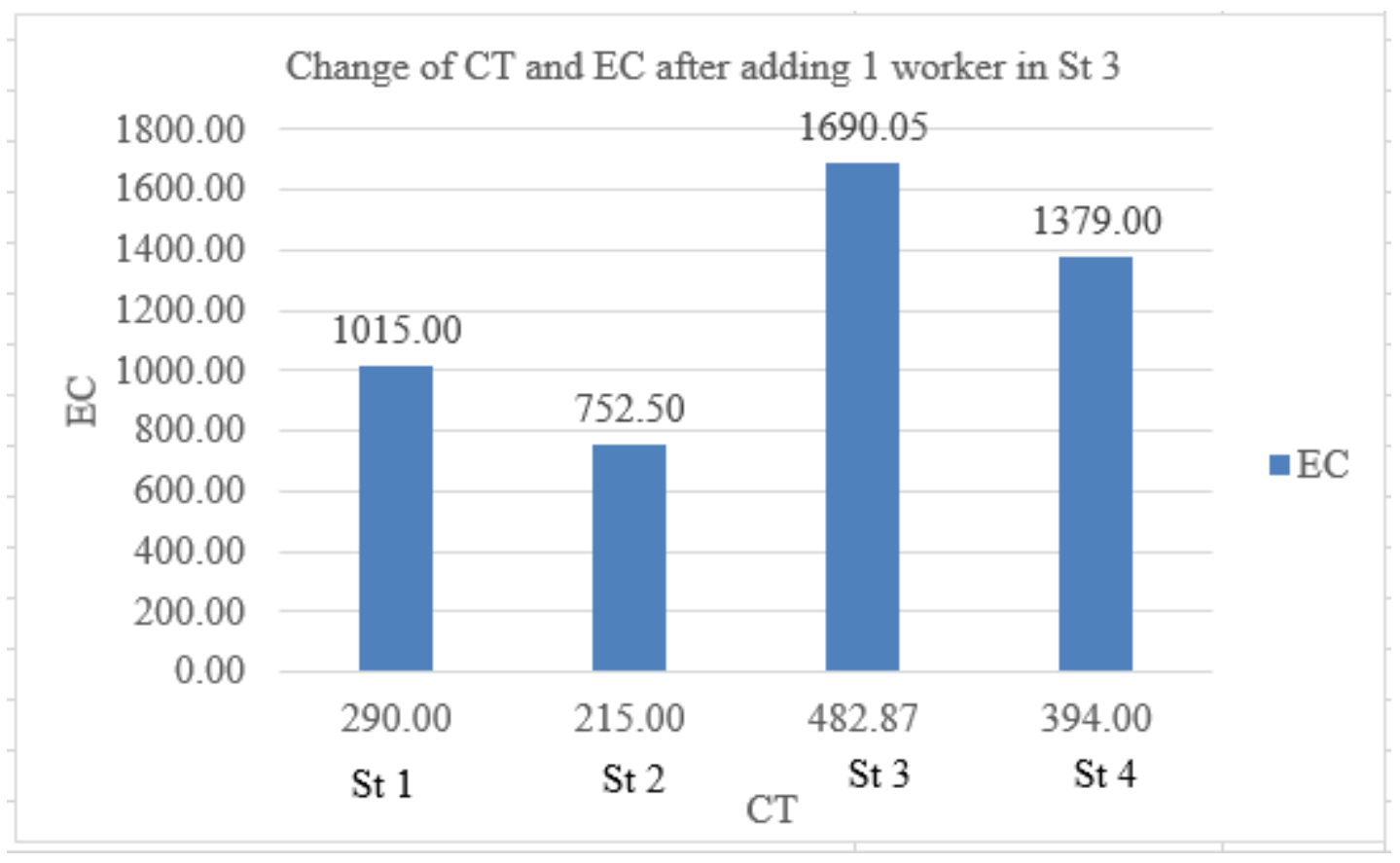

Figure 21. Future scenario of energy consumption after adding 1 worker at St 3.

Figure 21 shows that in St 3, CT could be reduced from 593 min to 482.87 min after adding one unit of labor. Consequently, EC is reduced from $2075.50 \mathrm{kw}$ to $1690.05 \mathrm{kw}$. 


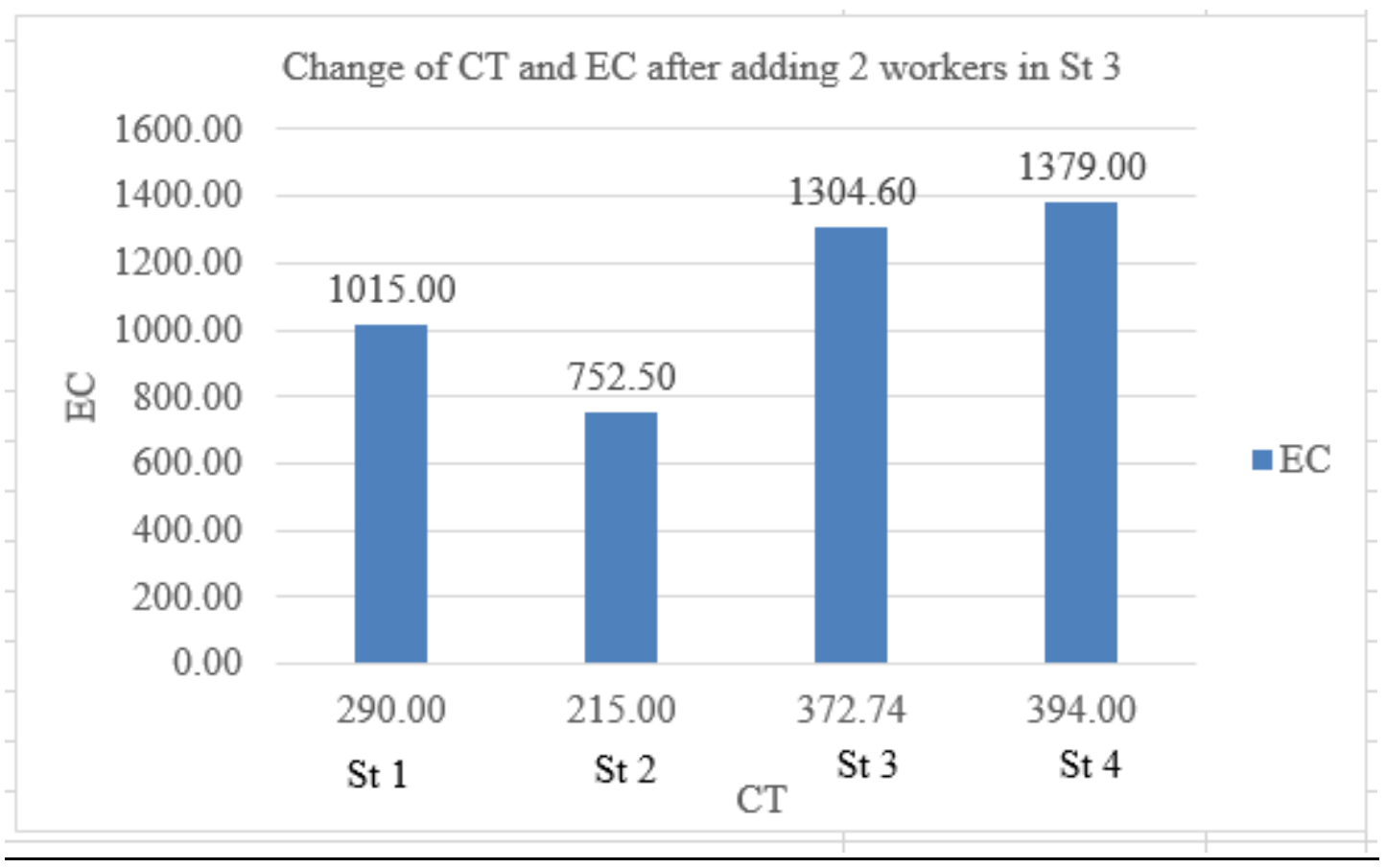

Figure 22. Future scenario of energy consumption after adding 2 workers at St 3.

Figure 22 shows that in St 3, CT could be reduced from $482.87 \mathrm{~min}$ to $372.74 \mathrm{~min}$ after adding two units of labor. Consequently, EC is reduced from $1690.05 \mathrm{kw}$ to $1304.60 \mathrm{kw}$. 


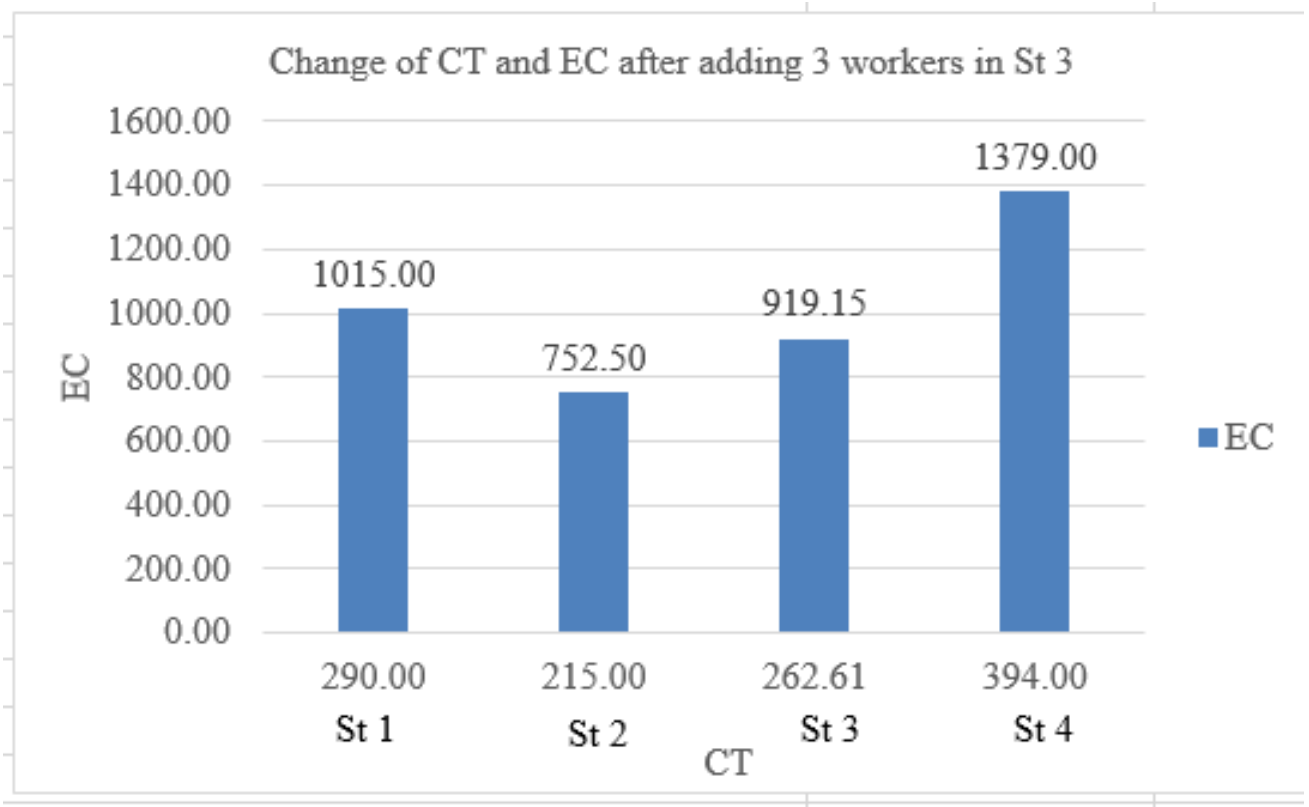

Figure 23. Future scenario of energy consumption after adding 3 workers at St 3.

Figure 23 shows that in St 3, CT could be reduced from 372.74 min to 262.61 min after adding three units of labor. Consequently, EC was reduced from $1304.60 \mathrm{kw}$ to $919.15 \mathrm{kw}$. Since the units of labor were added from other stations, the total possible number of units of labor that could be added to St 3 was limited. Per calculations, this is the optimized situation.

\section{Findings and Results}

The p-value is a number between 0 and 1 , which is used to weigh the strength of the evidence. A small p-value (<=0.05) indicates strong evidence against the null hypothesis and a large p-value $(>=0.05)$ indicates weak evidence against the null hypothesis. Based on the statistical analysis here, the p-value of one tail was 0.01 , less than 0.05 , which means the data sample provided enough evidence to reject the null hypothesis. The application of Lean Six Sigma cannot reduce the energy consumption. With the verification of loosely coupled multi-unit system, the largest eigenvalue of Activity D (Interior Wall Finish-Dry Wall (Interior Finish)) was 
271.25. It indicated that Activity D was most likely to be responsible for the root causes of the inefficiency problem in energy consumption and needed to be improved first.

For the verification of System Dynamics system, the system ran for the duration of cycle time. The energy consumption at station 1 was $1015 \mathrm{kw}$. The red minus sign on the left means that power of equipment and material were being consumed during the process. The energy consumptions were $752.50 \mathrm{kw}, 2075.50 \mathrm{kw}$ and $1379 \mathrm{kw}$ for stations 2,3 and 4 respectively.

In the Discrete Optimization process, the first focus was on Station 3 because the processing rate in Station 3 was the lowest, which was $0.12 \%$ per minute. Its cycle time (CT) and energy consumption (EC) were highest too among other stations. The results showed that for every additional unit of labor in St3, CT could be reduced by 110.13 minutes leading to a savings of $385.46 \mathrm{kw}(110.13 * 3.5)$ per labor. Fig. 21,22 and 23 show that after adding up to 3 units of labor one by one, CT was reduced from $593 \mathrm{~min}$ to $482.87 \mathrm{~min}$, from $482.87 \mathrm{~min}$ to $372.74 \mathrm{~min}$ and from 372.74 min to 262.61 min respectively. Thus, EC was reduced from $2075.50 \mathrm{kw}$ to $1690.05 \mathrm{kw}$, then to $1304.60 \mathrm{kw}$ and finally to $919.15 \mathrm{kw}$ respectively in Station 3.

From the data analysis results, it was found that the data samples were statistically significant and application of Lean Six Sigma technique could greatly increase the processing rate of Station 3, which consequently reduced the cycle time (CT) and energy consumption (EC). 


\section{CHAPTER V: SUMMARY, CONCLUSION AND RECOMMENDATIONS}

\section{Summary}

The purpose of this study was to identify the non-value adding tasks based on cycle time analysis and possible causes of unnecessary long cycle time in modular construction in order to reduce process energy consumption. To accomplish that task, a model was built using Lean Six Sigma technique. The proposed model will help the modular construction industry to reduce the energy consumption. It was important to develop a model with the potential to quantitatively verify the effectiveness of Lean Six Sigma in manufacturing of modular construction.

The quantitative method utilized in this research was based on the RSMeans Building Construction Cost Data for determining appropriate task times. Autodesk's Revit was used to design the modules.. Data analysis was accomplished by utilizing Microsoft Excel and AnyLogic Simulation software.

\section{Conclusion}

The research question of this thesis was whether the application of Lean Six Sigma can reduce the energy consumption of modular construction. Before answering this question, other questions were raised, namely: a) What are the factors that cause the energy inefficiency? b) What are the root causes of these factors? c) How can the statistically significance of the data be verified? Quantitative research methods were used to develop an answer for each of these questions.

The demand for building modules continues to increase due to the many benefits that modular fabrication and construction can bring to customers and manufacturers. Reduction of process energy consumption is important for the modular building industry to control the cost of the production. This research used a Lean method to identify the waste in a production process. 
However, lean methodologies do not provide a root cause analysis to eliminate the waste. For that reason, Six Sigma method was integrated with Lean in this research. Lean Six Sigma combined Lean tool Value Stream Mapping with DMAIC of Six Sigma method to reduce the cycle time-resulting in increased energy efficiency. Lean Six Sigma was applied throughout the research process and VSM was applied first to identify the waste before focusing on how to reduce those waste by DMAIC process.

As a Lean method, Value Stream Mapping (VSM) was used to identify value added and non-value added activities of the current system. The factors identified as waste factors were longer cycle time, defects, longer takt time and change over time. In this research, the equipment and processing system kept running during cycle time. Hence, if non-value added activities happened during cycle time, they were considered as the waste factor of the energy consumed. Using the DMAIC process of the Six Sigma methodology, the root causes of the factors were identified. The factors of Machines, Methods, People, Environment, Measurement system and Material were identified as potential root causes of the problem. The Method of the production system (i.e. how work is done) was identified as a major factor responsible for longer cycle time. These factors were confirmed and verified using the Loosely Coupled Multi-Unit System and System Dynamics process respectively. Loosely Coupled Multi-Unit System showed how loosely the six root causes identified were inter-connected to each other. System Dynamics process verified the waste factors identified and showed how a change in cycle time (CT) changed the energy consumption of a system. To verify the significance of the data collected, a hypothesis test called two-sample-paired t- test was carried out.

For the existing production system, the assumption was that the processing rates of tasks would not increase. Usually in modular construction, the rate at which a task is done is very 
important in order to decrease the overall cycle time and increase efficiency. To increase the processing rate, the process is coordinated by the production team that spends their time in planning a schedule, identifies idle workers to move them in different stations, and reduces the change over time. In this research, the tasks of all the stations were operated sequentially.

It was found from the collected data that processing rate in Station 3 (St 3) was $0.12 \% / \mathrm{min}$, lower than any other station in the process, which led to longer cycle time due to an increase in waiting time and amount of work in process (WIP) between Station 2 and Station 3. The reason of WIP was that since Station 3 had lower processing rate than its immediate predecessor station, which was Station 2. The completion rate of Station 3 was slower than that of Station 2. Therefore, it could not synchronize 100\% with Station 2, which was processing and feeding the tasks at a faster rate to its successor station. As a result, some tasks of Station 2 had to wait between the Stations 2 and 3 because of difference in processing rate between Station 2 and 3, until the crews of Station 3 were ready to accept those tasks. This caused Station 3 to have a longer cycle time (CT) and higher energy consumption (EC), with 593 min and $2075.50 \mathrm{kw}$ respectively. The CT and EC of Station 3 were higher than any other stations in the system. Therefore, a new method was required to optimize the existing process in order to reduce its cycle time and consequently, energy consumption.

This research optimized the manufacturing process through the application of the Lean Six Sigma technique. Though all the stations showed possible areas for improvements, only Station 3 was considered for improvement due to its lowest processing rate and long cycle time. Because of its lowest processing rate, the number of units produced per time was lower in Station 3 than any other stations. Its longer cycle time led to running equipment for a longer duration, which consequently caused the increase of the energy consumption. As part of the 
optimization process, workers were moved to different stations in order to keep the cycle time as close as possible to takt time. The reason to focus on managing the workers was because some of the workers were determined to be idle in Station 2. During the time period that workers were standing idle and since the production process operated in a sequential order, the tasks released from Station 2 were also waiting between Station 2 and Station 3 to be moved and processed to the next station, which was Station 3. Reassigning those idle workers to different stations helped increase the processing rate of Station 3. As a result, Station 3 was able to accept and process more task from Station 2 at a faster rate than before, which reduced the amount of time of the tasks that were waiting between Station 2 and 3. Thus it reduced the cycle time (CT). Having a p-value of 0.01 , which is less than 0.05 showed enough confidence to move forward against the null hypothesis that there is no difference in terms of energy savings after applying Lean Six Sigma technique in the system.

The implementation results of Lean Six Sigma technique showed that moving idle workers from different stations to Station 3 balanced the production line of module room manufacturing process and increased the processing rate of the Station 3, which was identified as a bottleneck. The increase of processing rate was from $0.12 \% / \mathrm{min}$ to $0.13 \% / \mathrm{min}$ (Figure 21,22 , 23), which consequently reduced the waiting time and thus reduced the cycle time of Station 3. As energy consumption increases with the increase in time spent in production process, reducing the cycle time of Station 3 helped to reduce the overall energy consumption of the process. The results showed that after applying Value Stream Mapping (VSM) as part of the Lean process, DMAIC as part of the Six Sigma, and adding up to 3 units of labor gradually in Station 3, cycle times (CT) were reduced by $18.6 \%, 37.14 \%, 55.7 \%$ when adding 1,2 , and 3 workers respectively. Since energy consumption (EC) and cycle time (CT) change in the same rate, the 
reduction of energy consumption (EC) were also $18.6 \%, 37.14 \%, 55.7 \%$ when adding 1,2 , and 3 workers respectively.

The implementation of this research depends on the understanding of Lean Six Sigma techniques. The author of this research toured a module home builder in Central Illinois recently and had a chance to talk to the owner of the company. The author found that this company has been applying a similar Lean technique and already been enjoying its benefits in the terms of faster construction time. But integrating Six Sigma with Lean could help the company to drive energy efficiency in success.

It may require some investment in training the people on applying the Lean Six Sigma technique. But the application results may bring long-term benefits to modular construction. As the demand of modular buildings is on the rise, application of this model would not only reduce the overall production cost in terms of energy savings, but also result in faster construction time and reduction of the cost of waste management. Another benefit includes the reduction of nonvalue adding activities. In addition, with less use of energy, it would contribute to the reduction of the $\mathrm{CO}_{2}$ emission to the environment and help tackle the climate changes.

\section{Recommendations}

The Lean Six Sigma production model developed in this thesis is based on a process to manufacture a simple module room. Implementation approaches of this model and the key strategies presented in this thesis could be generalizable for the modular construction industry. The methodology to apply value stream mapping and DMAIC proposed in this thesis can be followed by other modular construction industries in order to reduce the time needed to complete modules and energy expenses. The following items are recommendations for future research: 
(1) For simulation purpose, this research used the module manufacturing process of a residential project where a room module was built and different tasks were demonstrated. Similar studies may be conducted in the future for other types of modular buildings and facilities.

(2) The Value Stream Mapping (VSM) method was used in this research as a Lean tool to visually present the information and workflow of the process from receiving materials to delivery to end customers. It helped to identify the waste factors. Other processes such as Kaizen events may be used in the future to better allocate the resources of both time and people to reduce the usage of energy streams.

(3) The whole system of room-module production was divided into 4 stations in this research. Further research may be carried out on a module production system with more stations to study the effects of a more complex system on the application of the Lean Six Sigma method.

(4) The data used in this research were determined from RSMeans Residential Construction Cost data (2016). Further research may be carried out by collecting real time data from the modular construction industry in order to see more precise results.

(5) In this research, the energy consumptions on a station with lower processing rate and longer cycle time was reduced by increasing the processing rate and decreasing the cycle time. In order to achieve those, idling workers from different stations were moved and reassigned to other stations as needed. Other waste factors, such as moving time or number of defects may be taken into consideration in the future in order to build a system with high energy efficiency. 
Overall, applying Lean Six Sigma helped to reduce task times and thereby reduce energy consumption for the module manufacturing process. 


\section{REFERENCES}

Ahn, B. J. (2000). Six sigma management innovation for white-collar. Han Un, Seoul, Korea.

Al-Sudairi, A. A., Diekmann, J. E., Songer, A. D., and Brown, H. M. (1999). Simulation of construction processes: Traditional practices versus lean principles.” Proc., 7th Annual Conference of the International Group for Lean Construction (IGLC-7), Berkeley, California.

Anderson, C. N., \& Kovach, V. J. (2013). Reducing Welding Defects in Turnaround Projects: A Lean Six Sigma Case Study. Quality Engineering, 26 (2), pp. 168-181. doi: $10.1080 / 08982112.2013 .801492$

Abdelhamid, T. S. (2003). Six-sigma in lean construction systems: Opportunities and challenges. Proc., 11th Annual Conference of the International Group for Lean Construction (IGLC-11), Blacksburg, Virginia.

Azhar, S. (2011). Building Information Modeling (BIM): Trends, Benefits, Risks, and Challenges for the AEC Industry. Leadership and Management in Engineering, 11(3), pp. 241-252.

Aziz, R. F., \& Hafez, S.M. (2013). Applying Lean Thinking in Construction and Performance Improvement. Alexandria Engineering Journal, 52 (4), pp. 679-695. doi: 10.1016/j.aej.2013.04.008

Ballard, G. (2000). Lean Project Delivery System. White Paper No. 8, Lean Construction Institute.

Ballard, G., \& Howell, G. (1995). Toward Construction JIT. Proceedings of the 1995. ARCOM Conference, Association of Researchers in Construction Management, 
Sheffield, England.

Banawi, A., A. (2013). Improving Construction Processes by Integrating Lean, Green and Six-Sigma (Doctoral Dissertation). University of Pittsburgh, PA.

Construction, M., H. (2010). Prefabrication and Modularization: Increasing Productivity in Construction Industry. Smart Market Report.

Bertelsen, S., \& Koskela, L. (2002). Managing the Three Aspects of Production in Construction. Proceedings of the Tenth Annual Conference of the International Group for Lean Construction (IGLC-10), Gramado, Brazil.

Bektas, E., \& Sebastian, R. (2013). A legal blueprint for developing additional contractual conditions for BIM implementations, TNO (Unpublished Paper).

Becerik-Gerber, B., \& Rice, S. (2010). The perceived value of building information modeling in the U.S. building industry. Electronic Journal of Information Technology in Construction, 15, pp. 185-201.

Brauer, R. (2006). Safety and Health for Engineers, 2nd ed. Wiley-Interscience, John Wiley and Sons, New Jersey.

Breyfogle, III, F.W., Cupello, J.M., \& Meadows, B. (2001). Managing Six Sigma: A practical guide to understanding, assessing, and implementing the strategy that yields bottom-line success. John Wiley \& Sons, Inc., Danvers, MA.

Campbell, S., B. (2013). Sustainable Workflows for Permanent Modular Wood Construction.

Dajadian, A. S. \& Koch, C., D. (2014). Waste Management Models and their Applications on Construction Sites. International Journal of Construction Engineering and Management, 3(3), p.91-98. 
Diekmann, J. E., Krewedl, M., Balonick, J., Stewart, T. \& Won, S. (2004). Application of Lean Manufacturing Principles in Construction.

Dixon, W. (2010). The Impacts of Construction and Built Environment, Briefing notes, Willmott-Dixon Group.

Duce-Romero, K. (2016). No Time to Waste-Construction Waste Management.

Dye, W. E., \& Sapp, J. B. (1990). Occupational Safety and Health Program Employee Handbook, Texas Southern University.

Elbeltagi, E., \& Dawood, M. (2011). Integrated visualized time control system for repetitive construction projects. Automation in Construction, 20(7), 940-953. doi: 10.1016/j.autcon.2011.03.012

Feng, Y., Y., Chen, Q., S. \& Zhang, X., L. (2012). System Dynamics Modeling for Urban Energy Consumption and $\mathrm{CO}_{2}$ emissions: A Case Study of Beijing, China.

Glassman, R. B. (1973). Persistence and loose coupling in living system. Behavioral Science. 18, pp. 83-98.

Green, S. D. (1999). The missing arguments of Lean Construction. Construction Management and Economics. 17(2), pp. 133-137.

Gidado, K. I. (1996). Project Complexity: the focal point of construction production planning. Construction Management and Economics, 14, pp. 213-225.

Grilo, A., \& Jardim-Goncalves, R. (2010). Value proposition on interoperability of BIM and collaborative working environments. Automation in Construction, 19(5), pp. 522530.

doi: 10.1016/j.autcon.2009.11.003

Goulding, J. S., Rahimian, F. P., Arif, M., \& Sharp, M. (2012). Off-Site Construction: 
Strategic Priorities for Shaping the Future Research Agenda. Architectoni.ca, Canadian Centre of Academic Art and Science (CCAAS), 1 (1), pp. 62-73.

Harry, M., \& Schroeder, R. (2000). Six sigma: The breakthrough management strategy revolutionizing the world's top corporations, Currency, New York.

Harris, F., \& McCaffer, R. (1997). Modern Construction Management. London: Blackwell Science.

Hammer, M., \& Goding, J. (2001). Putting Six Sigma in Perspective. Quality Magazine, Business New Publishing, October, pp. 58-62.

Howell, G. A. (1999). What is Lean construction? Proceedings, Annual Conference of the International Group for Lean Construction, Berkeley, CA, USA, Jul. 26-28,1-10.

Howell, G., \& Ballard, G. (1994). Implementing lean construction: reducing inflow variation, Proceedings of the Second Meeting of the International Group for Lean Construction, Santiago, Chile.

Alarcón, L., \& Balkema, A. A. (1997) Lean Construction, , Rotterdam, pp 93-100.

Han, S.H., Chae, M. J., Im, K.S., \& Ryu, H. D. (2008). Six Sigma-based approach to improve performance in construction operations, Journal of Management in Engineering, January, pp. 21-31.

Hamelin, M-C., \& Zmeureanu, R. (2012). Multi-objective life cycle optimization of a single-family house envelope.

Hopp, W., \& Spearman, M. (1996). Factory Physics: Foundations of Manufacturing Management. Irwin/McGraw-Hill. Boston, MA.

Hopp, W. J., \& Spearman, M. L. (2000). Factory physics, McGraw-Hill, New York. Howell, G., Ballard, G., and Hall, J. (2001). Capacity utilization and wait time: A premier 
for construction. Proc., 9th Annual Conf. of the Int. Group of Lean Construction, Santiago, Chile.

Keller, K., Clevenger, M. C., \& Atadero, R. (2013). Framework for Sustainability Challenges within the Building Industry.

Koskela, L. (1992). Application of the new production philosophy to construction. Tech. Report 72, CIFE, Stanford University.

Koskela, L. (2000). An Exploration into a Production Theory and Its Application to Construction. VTT Publications, 298. Helsinki University of Technology, Espoo, Finland.

Kwaka, Y. H., \& Anbari, F. T. (2006). Benefits, Obstacles and Future of Six Sigma Approach. Technovation. 26 (5-6). pp. 708-715.

Lindermann, K., Schroeder, R. G., Zaheer, S., \& Choo, A. S. (2003). Six sigma: A goaltheoretic perspective. Journal of Operations Management. 21(2), pp. 193-203.

Liu, J., J., Hou, L. \& Wang, Y. X. (2014). A Discrete Firefly Algorithm for the Scaffolding Modular Construction in Mega Projects.

Ma, Z., Wei, Z., Wu, S., \& Zhe, L. (2011). Application and extension of the IFC standard in construction cost estimating for tendering in China. Automation in Construction, 20(2), pp. 196-204. doi: 10.1016/j.autcon.2010.09.017

Meyers, E. F. (2002). Time Study Method Implementation in Manufacturing Industry.

Modular Building Institute (2010). Improving Construction Efficiency and Productivity with Modular Construction.

Mullens, A. M. \& Kelly, E. M. (2004). Lean Homebuilding using Modular Technology. 
National Institute of Standards and Technology (2004). Cost Analysis of Inadequate Interoperability in the U.S. Capital Facilities Industry. NIST GCR 04-867. Gaithersburg, MD.

National Research Council (2009). Advancing the Competitiveness and Efficiency of the U.S. Construction Industry.

Ohno, T. (1988). Toyota Production System. Productivity Press. New York, NY.

Ohno, T. (1990). Toyota production system: beyond large-scale production. New York: Productivity press.

Orton, J.D., \& Weick, K. E. (1990). Loosely Coupled System: A reconceptualization. Academy of Management Review, 15(2), pp. 203-23.

Pan, W., Gibb, A., \& Dainty, A. (2012): Strategies for Integrating the Use of Off-Site Production Technologies in House Building. Journal of Construction, Engineering and Management, 138(11), pp. 1331-1340.

Pande, P.S., Neuman, R.P., \& Cavanagh, R.R., (2000). The Six Sigma Way: How GE, Motorola, and Other Top Companies are Honing Their Performance. McGraw- Hill, New York.

Panneerselvam, R. (2013). Productions and Operations Management.

Peter, M. (2013). Innovation Imperative. Quality Progress, pp. 42 -44.

Plotner, C. S. (2016). RSMeans Building Construction Cost Data.

Pheng, L. S., \& Chuan, C. J. (2001). Just-in-time management of precast concrete components. Journal of Construction Engineering Management, 127(6), pp. 494-501.

Penttilä, H. (2006). Describing The Changes In Architectural Information Technology To 
Understand Design Complexity and Free-Form Architectural Expression. ITcon, 11, pp. 395-408. Retrieved from http://www.bimthinkspace.com/2008/01/the-bim episode.html

Qingdao Hegu Wood-Plastic Machinery Co., Ltd. 04 Sep. 2012, www.heguwpc.en.madein-china.com/product/HeAxadgXCFVu/China-Wood-Door-Panel-Machine- Wood-PVC-

Door-Panel-Making-Machine-SJSZ-92-188-.html. Accessed 29 Nov. 2016.

Quinn, J. D. (2008). Modeling the resource consumption of housing in New Orleans using System Dynamics.

R, S. T. (2014). A Study of Six Sigma and Its Importance. International Journal of Business Quantitative Economics and Applied Management Research, 1(5).

Sacks, R., Radosavljevic, M., \& Barak, R. (2010). Requirements for building information modeling based lean production management systems for construction. Automation in Construction, 19(5), pp. 641-655.

doi: 10.1016/j.autcon.2010.02.010

Sakamoto, M., Horman, M. J., \& Thomas, H. R. (2002). A study of the relationship between buffers and performance in construction. Proc., 10th Annual Conf. of the Int. Group of Lean Construction, Gramado, Brazil.

Schoenborn, M. J. (2012). A Case Study Approach to Identifying the Constraints and Barriers to Design Innovation for Modular Construction.

Schonberger, R. J. (1996). World Class Manufacturing: The Next Decade. The Free Press, New York, NY.

Snee, R. D. (2010). "Lean Six Sigma-Getting better all the Time”. International Journal of Lean Six Sigma, 1(1). p. 9-29.

Silver, M. (2011). Modular Construction preferred in Pennsylvania and New York. 
Sterman, D. J. (2002). System Dynamics: Systems Thinking and Modeling for a Complex World.

Tang, V. \& Vijay, S. (2001). System Dynamics: Origins, Development, and Future Prospect of a Method.

Force, C. T., \& Britain, G. (1998). Rethinking Construction: The report of the Construction Task Force to the Deputy Prime Minister, John Prescott on the scope for improving the quality and efficiency of UK construction. London: Department of the Environment, Transport and the Regions.

Tsao, C.C.Y., Tommelein, I.D., Swanlund, E., \& Howell, G.A. (2000). Towards Work Structuring: 5 WHYs Applied to Installation of Metal Door Frames. Technical Report No. 2000-03, Construction Engineering Management Program, Civil \& Environmental Engineering Department, University of California, Berkeley, CA.

Thomas, H. R., Horman, M. J., Souze, U. E., \& Zavrski, I. (2002). Reducing variability to improve performance as a lean construction principle. Journal of Construction Engineering and Management. 128(2), pp. 144-154.

Thomas, H. R., Horman, M. J., Minchin, E., \& Chen, D. (2003). Improving labor flow reliability for better productivity as lean construction principle. Journal of Construction Engineering and Management. 129(3), pp. 251-261.

Tommelein, I. D. (2000). Impact of variability and uncertainty on product and process development. Proc., 6th Construction Congress, ASCE, Reston, Va., pp. 969-976.

Tulacz, G., and Armistead, T. (2007). Large corporations are attempting to meet the industry halfway on issues of staff shortages and risk. Engineering News Record, November 26. 
U.S. Census Bureau (2010). Labor Force, Employment, \& Earnings by Industry.

Washington, DC. Retrieved September, 2016, from http://census.gov.

U.S. Department of Commerce (2016). Gross-Domestic-Product-(GDP)-by-Industry

Data. Washington, DC. Retrieved September, 2016, from http://bea.gov.

U.S. Environmental Protection Agency (2003). Construction and Demolition Materials

Amounts. Washington, DC. p. 1-27.

Underwood, J., \& Isikdag, U. (2010). Handbook of Research on Building Information

Modeling and Construction Informatics: Concepts and Technologies. Hershey, PA: IGI

Global, pp. 1-757. doi:10.4018/978-1-60566-928-1

Vyas, S., Ahmed, S. \& Parashar, A. (2014). BEE (Bureau of Energy Efficiency) and Green Buildings. International Journal of Research, 1, pp. 23-32

Waje, V. V., \& Patil, V. (2012). Cost of Poor Quality in Construction. IOSR Journal of Mechanical and Civil Engineering.

Weltman, D., \& Swink, M. (2015). Numerous Sigma Level Tables Need Correction. Commonly Used Tables Ignore Permitted 'Left-Side’ Defects. INFORMS Transactions on Education, 16(1), p. 1-5.

Wilson, L. (2010). How to Implement Lean Manufacturing. New York: McGraw-Hill

Womack, J. P., Jones, D.T., \& Roos, D. (1990). The Machine That Changed the World. Rawson Associates, New York.

Yilmaz, M., \& Bakis, A. (2015). Sustainability in Construction Sector.

Yu, H., Al-Hussein, M., Al-JIBOURI, S., \& TELYAS, A. (2013). Lean Transformation in a Modular Building Company. Journal of Management in Engineering, 29 (1).

Zawidzki, M., \& Nishikawa, I. (2010). Discrete optimization of modular truss network in 
a constrained network. 


\section{APPENDIX A: TERM DEFINITIONS}

The noteworthy terms in this study are defined in the table below. The definitions are ordered alphabetically.

Table 1: Definitions of Terms

\section{$\underline{\text { Acronym }} \underline{\text { Term }}$}

AEC Architecture,

Engineering and

Construction

BIM Building Information

Modeling

CAD Computer Aided

Design

DMAIC Define-Measure-

Analysis-

Improvement-

Control

DPMO Defects Per Million

Opportunities

DFSS Design For Six

Sigma

GDP Gross Domestic

Product

\section{$\underline{\text { Definitions }}$}

The sector of the construction industry that provides the services on the architectural design, engineering design and construction services.

BIM is a digital representation of physical and functional characteristics of a facility CAD is the use of computer systems to aid in the creation, modification, analysis, or optimization of a design

DMAIC is a data-driven quality strategy used to improve processes. It is an integral part of a Six Sigma initiative.

In process improvement efforts, DPMO is a measure of process performance.

DFSS is a business-process management "methodology" related to traditional Six Sigma GDP is one of the primary indicators used to gauge the health of a country's economy 
GE General Electric $\quad$ GE is an American multinational conglomerate
corporation.

IFC Industry Foundation IFC is the open and neutral data format

Class

JIT Just-In-Time

JIT is a methodology aimed primarily at reducing

flow times within production as well as response

times from suppliers and to customers

LPDS Lean Project It applies lean construction principles and tools to

Delivery System facilitate planning and control, maximize value and

minimize waste throughout the construction

process.

NIST National Institute of NIST is a federal technology agency that works

Standards and with industry to develop and apply technology,

Technology measurements, and standards.

NRC National Research NRC is the working arm of the National

Council Academies of Science, Engineering, and Medicine

of the United States that produces reports that

shape policies, inform public opinion, and advance

the pursuit of science, engineering, and medicine.

OSP Off-Site Production OSP refers to structures built at a different location than the location of use. 
TFV views production as a flow composed of value

Flows and Value

adding

VSM Value Stream

Mapping

WIP

CT

EC

$\mathrm{TH}$

$\mathrm{W}_{0}$

$\mathrm{Rb}$

$\mathrm{T}_{0}$

Work In Process

Cycle Time

Throughput

Critical WIP adding activities (transformation) and non-value adding activities (waiting, inspection and moving).

VSM is a lean-management method for analyzing the current state and design of a future state for the series of events that take a product or service from its beginning through to the customer.

WIP refers to a work that has entered the production process but is not yet finished.

Total time from the beginning to the end of the process. It includes processing time, changeover time, delay time, moving time etc.

Energy Consumption Consumption of energy or power.

Is the average quantity of modules (non-defective)

produced per unit time.

WIP level in which a line having no congestion

would achieve maximum throughput (i.e. $\mathrm{Rb}$ )

with minimum cycle time (i.e. T0).

Bottleneck Rate Is the rate of the process center having least

long-term capacity with highest long-term utilization.

Raw Processing Time Sum of long-term average processing time per piece of each work-station in a line. 


\section{APPENDIX B: DEFINE-MEASURE-ANALYSIS-IMPROVEMENT-CONTROL (DMAIC)}

DMAIC is a five-step Six-Sigma improvement model. It is commonly used by Six-Sigma firms to improve the current capabilities of an existing process. Several tools and methods can be used in each step of the DMAIC model. The DMAIC's five phases are presented in Table below.

\begin{tabular}{|c|l|}
\hline DMAIC Steps & \multicolumn{1}{|c|}{ Explanation } \\
\hline Define & Identify the problem and the issues \\
causing decreased customer satisfaction
\end{tabular}




\section{APPENDIX C: CHANGE OF CT AND EC AT DIFFERENT STATIONS AFTER ADDING WORKERS}

\begin{tabular}{|c|c|}
\hline Parameters & Station 3 \\
\hline Current CT (min) \& EC (kw) & 593 min and 2075.50 kw \\
labor & 482.87 min and 1690.05 kw \\
\hline CT (min) \& EC (kw) after adding 1 unit of & 372.74 min and $1304.60 \mathrm{kw}$ \\
\hline labor $(\min )$ \& EC (kw) after adding 2 units of & \\
\hline CT (min) \& EC (kw) after adding 3 units of & $262.61 \mathrm{~min}$ and $919.15 \mathrm{kw}$ \\
labor & \\
\hline
\end{tabular}




\section{APPENDIX D: CYCLE TIME (CT), COMPLETION RATE AND PROCESSING RATE OF 55 OBSERVATIONS.}

\begin{tabular}{|c|c|c|c|c|c|c|c|c|c|c|c|c|}
\hline Numbers & Cycle T & (min) & & & Comple & 1 rate( & & & rocess & rate ( & $\min )$ & \\
\hline & St 1 & St 2 & St 3 & St 4 & St 1 & St 2 & St 3 & St 4 & St 1 & St 2 & St 3 & St 4 \\
\hline 1 & & & & & 70 & 70 & 70 & 70 & 0.24 & 0.33 & 0.12 & 0.18 \\
\hline 2 & & & & & 97 & 75 & 72 & 80 & 0.33 & 0.35 & 0.12 & 0.20 \\
\hline 3 & & & & & 97 & 92 & 84 & 78 & 0.33 & 0.43 & 0.14 & 0.20 \\
\hline 4 & & & & & 79 & 79 & 82 & 85 & 0.27 & 0.37 & 0.14 & 0.22 \\
\hline 5 & & & & & 85 & 84 & 83 & 73 & 0.29 & 0.39 & 0.14 & 0.19 \\
\hline 6 & & & & & 74 & 85 & 93 & 73 & 0.26 & 0.40 & 0.16 & 0.19 \\
\hline 7 & & & & & 79 & 86 & 96 & 95 & 0.27 & 0.40 & 0.16 & 0.24 \\
\hline 8 & 290 & 215 & 593 & 394 & 91 & 95 & 82 & 89 & 0.31 & 0.44 & 0.14 & 0.23 \\
\hline 9 & & & & & 77 & 92 & 94 & 82 & 0.27 & 0.43 & 0.16 & 0.21 \\
\hline 10 & & & & & 72 & 83 & 89 & 70 & 0.25 & 0.39 & 0.15 & 0.18 \\
\hline 11 & & & & & 99 & 74 & 96 & 72 & 0.34 & 0.34 & 0.16 & 0.18 \\
\hline 12 & & & & & 71 & 86 & 85 & 93 & 0.17 & 0.40 & 0.09 & 0.24 \\
\hline 13 & & & & & 70 & 97 & 86 & 72 & 0.24 & 0.45 & 0.15 & 0.18 \\
\hline 14 & & & & & 96 & 91 & 73 & 70 & 0.33 & 0.42 & 0.12 & 0.18 \\
\hline 15 & & & & & 78 & 97 & 73 & 100 & 0.27 & 0.45 & 0.12 & 0.25 \\
\hline 16 & & & & & 85 & 77 & 97 & 77 & 0.29 & 0.36 & 0.16 & 0.20 \\
\hline 17 & & & & & 76 & 94 & 95 & 80 & 0.26 & 0.44 & 0.16 & 0.20 \\
\hline 18 & & & & & 96 & 80 & 71 & 93 & 0.33 & 0.37 & 0.12 & 0.24 \\
\hline 19 & & & & & 95 & 85 & 98 & 85 & 0.33 & 0.40 & 0.17 & 0.22 \\
\hline 20 & & & & & 76 & 95 & 82 & 77 & 0.26 & 0.44 & 0.14 & 0.20 \\
\hline 21 & & & & & 100 & 93 & 79 & 83 & 0.34 & 0.43 & 0.13 & 0.21 \\
\hline 22 & & & & & 98 & 97 & 75 & 97 & 0.34 & 0.45 & 0.13 & 0.25 \\
\hline 23 & & & & & 95 & 87 & 80 & 85 & 0.33 & 0.40 & 0.13 & 0.22 \\
\hline 24 & & & & & 98 & 87 & 72 & 76 & 0.34 & 0.40 & 0.12 & 0.19 \\
\hline 25 & & & & & 99 & 76 & 99 & 99 & 0.34 & 0.35 & 0.17 & 0.25 \\
\hline 26 & & & & & 95 & 76 & 100 & 86 & 0.33 & 0.35 & 0.17 & 0.22 \\
\hline 27 & & & & & 93 & 76 & 95 & 72 & 0.32 & 0.35 & 0.16 & 0.18 \\
\hline 28 & & & & & 100 & 71 & 81 & 100 & 0.34 & 0.33 & 0.14 & 0.25 \\
\hline 29 & & & & & 81 & 92 & 76 & 92 & 0.28 & 0.43 & 0.13 & 0.23 \\
\hline 30 & & & & & 75 & 99 & 86 & 78 & 0.26 & 0.46 & 0.15 & 0.20 \\
\hline 31 & & & & & 93 & 83 & 95 & 79 & 0.32 & 0.39 & 0.16 & 0.20 \\
\hline 32 & & & & & 84 & 94 & 100 & 95 & 0.29 & 0.44 & 0.17 & 0.24 \\
\hline 33 & & & & & 99 & 94 & 72 & 77 & 0.34 & 0.44 & 0.12 & 0.20 \\
\hline 34 & & & & & 76 & 97 & 93 & 86 & 0.26 & 0.45 & 0.16 & 0.22 \\
\hline 35 & & & & & 79 & 80 & 74 & 83 & 0.27 & 0.37 & 0.12 & 0.21 \\
\hline 36 & & & & & 82 & 84 & 89 & 85 & 0.28 & 0.39 & 0.15 & 0.22 \\
\hline 37 & & & & & 80 & 85 & 78 & 85 & 0.28 & 0.40 & 0.13 & 0.22 \\
\hline 38 & & & & & 91 & 88 & 75 & 81 & 0.31 & 0.41 & 0.13 & 0.21 \\
\hline 39 & & & & & 87 & 73 & 87 & 80 & 0.30 & 0.34 & 0.15 & 0.20 \\
\hline 40 & & & & & 99 & 97 & 97 & 74 & 0.34 & 0.45 & 0.16 & 0.19 \\
\hline 41 & & & & & 95 & 76 & 100 & 94 & 0.33 & 0.35 & 0.17 & 0.24 \\
\hline 42 & & & & & 95 & 97 & 74 & 74 & 0.33 & 0.45 & 0.12 & 0.19 \\
\hline 43 & & & & & 91 & 98 & 84 & 84 & 0.31 & 0.46 & 0.14 & 0.21 \\
\hline 44 & & & & & 71 & 88 & 78 & 84 & 0.24 & 0.41 & 0.13 & 0.21 \\
\hline 45 & & & & & 87 & 97 & 73 & 93 & 0.30 & 0.45 & 0.12 & 0.24 \\
\hline 46 & & & & & 73 & 83 & 73 & 81 & 0.25 & 0.39 & 0.12 & 0.21 \\
\hline 47 & & & & & 99 & 86 & 92 & 91 & 0.34 & 0.40 & 0.16 & 0.23 \\
\hline 48 & & & & & 90 & 76 & 87 & 79 & 0.31 & 0.35 & 0.15 & 0.20 \\
\hline 49 & & & & & 94 & 87 & 76 & 88 & 0.32 & 0.40 & 0.13 & 0.22 \\
\hline 50 & & & & & 85 & 95 & 93 & 85 & 0.29 & 0.44 & 0.16 & 0.22 \\
\hline 51 & & & & & 83 & 86 & 89 & 70 & 0.29 & 0.40 & 0.15 & 0.18 \\
\hline 52 & & & & & 86 & 70 & 79 & 83 & 0.30 & 0.33 & 0.13 & 0.21 \\
\hline 53 & & & & & 83 & 92 & 89 & 87 & 0.29 & 0.43 & 0.15 & 0.22 \\
\hline 54 & & & & & 91 & 72 & 80 & 86 & 0.31 & 0.33 & 0.13 & 0.22 \\
\hline 55 & & & & & 96 & 75 & 94 & 74 & 0.33 & 0.35 & 0.16 & 0.19 \\
\hline
\end{tabular}

